Portland State University

PDXScholar

Business Faculty Publications and

Presentations

The School of Business

$1-1-2019$

\title{
A Review and Synthesis of the Work Ability Literature
}

David Cadiz

Portland State University, dcadiz@pdx.edu

Grant Brady

Portland State University, brady5@pdx.edu

Jennifer R. Rineer

RTI International

Donald M. Truxillo

Portland State University, truxillod@pdx.edu

Follow this and additional works at: https://pdxscholar.library.pdx.edu/busadmin_fac

Part of the Business Commons

Let us know how access to this document benefits you.

\section{Citation Details}

Cadiz, D. M., Brady, G., Rineer, J. R., \& Truxillo, D. M. (2019). A Review and Synthesis of the Work Ability Literature. Work, Aging \& Retirement, 5(1), 114-138. https://doi.org/10.1093/workar/way010

This Post-Print is brought to you for free and open access. It has been accepted for inclusion in Business Faculty Publications and Presentations by an authorized administrator of PDXScholar. Please contact us if we can make this document more accessible: pdxscholar@pdx.edu. 


\section{OXFORD} UNIVERSITY PRESS

\section{Work, Aging and Retirement}

\section{A Review and Synthesis of the Work Ability Literature}

\begin{tabular}{|r|l|}
\hline Journal: & Work, Aging and Retirement \\
\hline Manuscript ID & WORKAR-2017-013.R4 \\
\hline Manuscript Type: & Annual Review Issue \\
\hline Keywords: & $\begin{array}{l}\text { Health < Aging and Individual Differences, Workability < Work, Phyiscal } \\
\text { aging < Aging and Individual Differences, Aging and Individual Differences, } \\
\text { Aging workforce, Review }\end{array}$ \\
\hline \multicolumn{2}{|l}{} \\
\hline
\end{tabular}

\section{SCHOLARONE ${ }^{\text {m }}$ \\ Manuscripts}




\section{WORK ABILITY REVIEW}

\section{A Review and Synthesis of the Work Ability Literature}

As workforces in industrialized countries continue to age, societal and organizational practices must address this change. To meet this challenge, researchers in Finland in the 1980s began studying the concept of work ability and developed the Work Ability Index (WAI) to better understand how long individuals should be expected to continue working (Ilmarinen, Tuomi, Eskelinen, Nygård, Huuhtanen, \& Klockars, 1991a). Work ability (WA) has been defined as a person's ability, or perceptions of their ability, to meet the demands of their job (Ilmarinen, et al., 1991a, Ilmarinen, 2009) ${ }^{1}$. Inherent in this definition is that WA is not only a function of one's personal capacities (e.g., physical and mental abilities) but also the requirements of the job. Thus, a person's WA may vary from one occupation to another.

In their initial research, Ilmarinen and colleagues (1991a, 1991b) found that WA generally decreases with age, and that those over 50, particularly those working in manual labor occupations, were most at risk for having poor WA (Ilmarinen et al., 1991b). Since these initial studies, WA has been shown in a number of longitudinal studies to predict important individual, organizational, and societal outcomes including retirement age, future disability status, job attitudes, and even mortality (McGonagle, Fisher, Barnes-Farrell, \& Grosch, 2015; Salonen, Arola, Nygård, Huhtala, \& Koivisto, 2003; von Bonsdorff, Huuhtanen, Tuomi, \& Seitsamo, 2009; von Bonsdorff et al., 2011). Given the predictive power of WA, its use has rapidly expanded, and researchers have sought to better understand WA's antecedents as a way to maintain and enhance it. Researchers have identified that WA is influenced by organizational factors, such as job demands (McGonagle et al., 2015) and job resources (e.g., supervisor support; Elo, Ervasti, Kuosma, \& Mattila, 2008), which points to the fact that organizations can

\footnotetext{
${ }^{1}$ Throughout our review, when we refer to work ability (WA) it is in reference to the concept of work ability. When we refer to the Work Ability Index (WAI), this is in specific reference to the measurement of work ability via the Work Ability Index developed by Ilmarinen and colleagues (1991a).
} 
influence employees' WA. With increasing concerns about aging workforces, the necessity of extending workers' careers to stabilize retirement systems, and the need for succession planning, understanding how to develop and maintain WA among employees may be particularly helpful. Although WA research has been rapidly increasing over the past decade, there has yet to be a comprehensive qualitative review of the extant literature. Therefore, we set out to provide this much-needed review to facilitate future scientific exploration of this increasingly important concept.

Although the importance of WA and interest in it are evident, there are three underlying issues with the WA construct and measurement that have yet to be reconciled. First, the haphazard way that WA has been operationalized and measured is limiting our understanding of the construct. For instance, the number of WA measures has proliferated rapidly, and there are fundamental differences in what each of these measures assess. In fact, one of the most neglected issues surrounding WA is the conceptual and theoretical distinction between objective WA (e.g., including diagnosed medical conditions) and perceived WA (based strictly on a respondent's perceptions). Yet relatively little research has explicitly studied differences among WA measures. In this review, we will explore and discuss the utility, advantages, and disadvantages of various WA measures, focusing our attention on the distinction between objective and perceived WA. Second, the vast majority of WA research, especially outside of the industrial and organizational psychology (IO) literature, has been essentially atheoretical. Put simply, the advancement of the WA construct has followed the proverbial path of "putting the cart before the horse." This review will retroactively investigate WA's nomological network, highlight recent integrations of WA research into the IO literature, and couch research from other disciplines within the framework of the job-demands resources (JD-R) model (Demerouti, Bakker, 
Nachreiner, \& Schaufeli, 2001). Further, we will discuss how lifespan development theories, specifically selection, optimization, and compensation theory (SOC; Baltes \& Baltes, 1990) and socioemotional selectivity theory (SST; Carstensen, Isaacowitz, \& Charles, 1999), can provide insight into WA research within the IO literature. Third, although research interest in WA has increased, the existing literature has remained largely fragmented among the medical, organizational, and related literatures. We address this gap by summarizing and synthesizing relevant cross-disciplinary WA research to provide a more comprehensive understanding of the WA literature. Finally, we identify several areas for future WA research.

\section{How Is WA Measured?}

A simple answer to the title of this section is that WA is currently operationalized and measured inconsistently. To understand how the field got to this point, we must go back to when the WA construct was originally conceptualized and developed. Ilmarinen and colleagues (1991a) developed the WA construct within the occupational medicine literature as a way to understand whether individuals were able to continue working given the physical and psychological requirements of their jobs. As such, it was not created with a focus on scale construction principles typically used in psychological research, such as focusing on construct definition and psychometric properties of the scale. However, as WA is being integrated into the IO literature, the lack of these important psychometric and conceptual properties is becoming more apparent. Hinkin's (1998) framework for construct and scale development is widely used within the IO literature, and describes a multistep process for developing measurement scales. Two requirements included in Hinkin's approach are, first, having a clear theoretical articulation of the construct's definition and content domain, and second, the establishment of the construct's nomological network. 
In terms of construct definition, Tuomi et al. (1997) describe WA as "How good is the worker at present, in the near future, and how able is he or she to do his or her work with respect to work demands, health, and mental resources?" (Tuomi et al., 1991; p. 67). According to these authors, this definition formed the basis for the seven dimensions of the WAI, although other definitions of WA have been less detailed. Thus, it is not entirely clear if WA is a single overarching construct, or a composite of several related but distinct factors. To Hinkin's second point, although there is substantial evidence that the scale relates to disability and withdrawal from work, a clear nomological network with recognized constructs was not established in the initial WA studies (e.g., Ilmarinen, Tuomi, \& Klockars, 1997; Tuomi et al., 1991).

\section{Work Ability Measurement Issues}

In the subsequent paragraphs, we critically examine issues with 1) the initial measurement of WA via the WAI, 2) the more recent operationalization of WA, 3) the conceptual distinction between objective and perceived WA, and 4) the relationships between WA and existing work-related constructs (e.g., person-job fit). Because detailing the extant WA measures is beyond the scope of this review, we created a table to summarize the characteristics of the most frequently used WA measures (see Table 1).

Initial measurement of WA. We start our discussion of WA measurement issues by summarizing the development of the original measure of WA, the Work Ability Index (WAI). The WAI emerged from a multidisciplinary group, which included experts representing physiology, psychology, medicine, epidemiology, and biostatistics (Ilmarinen, et al., 1991a). The WAI includes seven dimensions and 60 items, which assess (1) current WA relative to lifetime best, (2) WA relative to the demands of the job, (3) number of physician-diagnosed diseases (indicated by the participant on a checklist of 50 potential diseases), (4) assessment of 
impairment due to illness or injury, (5) number of sick leave days over the last year, (6) an assessment of whether in two years the person will be able to perform their job from a health standpoint, and (7) an assessment of mental resources used on the job over the last 3 months. Scores on each dimension are summed, with a range from 7-49 (see Morschhäuser \& Sochert, 2006) for a detailed description of the WAI scoring). To make it easier to describe differences in WA, the researchers created WAI cutoff scores for four categories of WA ranging from 'poor' to 'excellent' (Tuomi et al., 1991). Based on initial promising results, the WAI was widely adopted and is now available in at least 30 languages (Ilmarinen, 2009).

Despite its extensive use, there are concerns related to the construct validity and psychometric qualities of the WAI. First, the WAI is scored using multiple weighting formulas and response formats across the seven dimensions (Ilmarinen et al., 1991b; Ilmarinen, 2009), and scoring for one dimension even differs by occupation. In addition, comprehensive studies testing the validity and generalizability of the weighting formulas across countries, work environments, and demographic groups are lacking, which could limit the utility of the WAI. Indeed, while most research uses the cutoff scores from the published WAI, others have argued that the cutoff scores should be adjusted based on the age of the sample (Kujala, Remes, Ek, Tammelin, \& Laitinen, 2005). Second, the use of cutoff scores to describe differences in WA is problematic because important information is lost when people are grouped into a limited number of categories. For example, there are substantive differences between someone with a WAI score of 28 and someone with a score of 36 that are not observed when using these categories. Moreover, using artificial categories results in reduced statistical power. A final notable concern relates to the practical administration of the WAI. Specifically, the WAI is relatively long (60 items) and contains personal health information (i.e., specific diagnosed diseases), which employees may 
not want to divulge to researchers or their organizations. These limitations and concerns with the WAI have catalyzed a proliferation of WA measures, and the limitations of these adaptations are captured in the subsequent sections.

Concerns with more recent WA measures. To address the practical constraints of the lengthy, original WAI, researchers started to adapt the WAI by reducing the number of items used to measure WA. For example, the creation of the WAI short form was one of the first adaptations to reduce the number of items of the original WAI (Nübling, Hasselhorn, Seitsamo, \& Ilmarinen, 2004). In the short-form WAI, the checklist that asks participants to indicate if they have any of the 50 specific physician-diagnosed diseases/illnesses is replaced with only 13 categories where participants indicate whether they have any of listed physician-diagnosed diseases/illnesses. The remaining six dimensions are measured using the same items as the original WAI. Although these changes address some of the concerns regarding the length of the survey, respondents are still asked to provide personal health information, which they may be uncomfortable providing to their employer. Moreover, the cutoff scores and categorizing are still retained in the WAI short form which are critical limitations of this measure.

The WA short form catalyzed a variety of adaptations that have further reduced the number of items used to measure WA, and more recent measures have begun to omit the objective items (e.g., diagnosed diseases and injuries) entirely. One key example is the singleitem Work Ability Score, which is simply the first item from the WAI: "Compared to your lifetime best, how would you rate your current work ability?” Ahlstrom and colleagues (2010) found that the single item WA score is a sufficient alternative to the WAI, and this finding spurred additional WA measures that eliminated aspects of objective WA. However, their research included only a limited number of correlates and only included women currently on 
disability. Additional research using the one-item Work Ability Score has shown mixed results: some have found supporting evidence of the measure's validity in larger and more representative samples (von Bonsdorff et al., 2012; El Fassi et al., 2013), while others have found the Work Ability Score to provide less utility for predicting long-term sickness absence compared to the WAI and WAI-short form (Roelen et al., 2014; Schouten et al., 2015). We recommend discontinuing the use of one-item measures of WA for several reasons. First, there is a lack of theory as to why one item would sufficiently capture the complex concept of WA (i.e., how does removing the objective health indicators impact the construct theoretically?). Further, it is still unclear how the WA Score compares to the original WAI or the short-form WAI measures regarding its predictive utility and nomological network with a number of occupational factors (i.e., job demands and resources) and long-term outcomes (e.g., retirement age).

Conceptual distinction between objective and perceived WA. A final important concern regarding WA measurement is the lack of conceptual distinction between objective and perceived aspects of WA. This issue stems from the original operationalization of WA and proliferation of WA measures in response to the WAI's limitations. First, the WAI combines objective and perceived indicators of WA into a single composite score. To be clear, when referring to objective indicators of WA, we are referring to the checklist in the WAI where participants indicate if they have specific physician-diagnosed diseases, injuries, and illnesses, as well as indicating whether they have been on sick leave in the past 12 months. In other words, because responses to this section of the WAI are based on a clinical diagnosis, we consider these a more objective indicator of one's physical, mental, and emotional ability to meet demands. Arguably, therefore, objective health-related WA may best reflect or capture actual physical and mental WA because they are driven in part by biological and physiological changes over the 
lifespan, whereas perceived WA may be more sensitive to individual characteristics (e.g., personality) and aspects of the environment (e.g., work demands and resources) because of its reliance on people's perceptions. Importantly, this two-dimension conceptual distinction does not mean that we think of these components as completely independent from each other. That is, because people often have a realistic perception of their abilities, we view objective healthrelated WA and perceived WA as interrelated facets of the broader WA construct. For instance, Eskelinen and colleagues (1991) found that there was a significant relationship between selfreported WA and clinically assessed indicators of WA at the group level. However, $\mathrm{Ng}$ and Feldman's (2013) meta-analytic investigation of age and health supports the idea the distinction between perception and reality in that they found no relationship between self-reported physical health problems and age, but a significant negative relationship between age and clinical indices of physical health such as blood pressure, cholesterol level, and body mass index. Thus, even though the WAI is treated as a single construct, some have argued and found evidence for two distinct, but related WA factors (i.e., a more objective health-related and a perceived component) and shown that this structure is more appropriate for the WAI (Martus, Jakob, Rose, Seibt, \& Freude, 2010; Radkiewicz et al., 2005).

Relatedly, the need for a conceptual distinction between a more objective health-related WA and perceived WA has become more apparent as researchers have attempted to address practical administration concerns of the WAI by reducing the number of items and removing the more objective indicators of WA (i.e., the physician-diagnosed health issues). For example, as the WA concept has become integrated into the IO literature, researchers have almost exclusively focused on the perceived WAI items (e.g., McGonagle et al., 2015; Palermo, Fuller-Tyszkiewicz, Walker, \& Appannah, 2013; Weigl, Müller, Hornung, Zacher, \& Angerer, 2013). McGonagle 
and colleagues' $(2014 ; 2015)$ perceived work ability measure, which is largely based on the perceived WA items from the WAI, provides a great example of how the researchers have shifted away from the objective component of WA. However, through the development of their measure, the researchers acknowledge that a distinction should exist between one's perception of their WA and clinical health indicators (i.e., biological, physiological) of WA. In other words, perceived work ability is independent from the assessment of WA by others - a requirement in the original WAI (i.e., the clinical diagnosis of diseases). Measures of perceived work ability are promising based on the job demands-resources model, but due to its recent introduction to the literature, more research is needed to replicate these findings.

The conceptual distinction between the two primary aspects of WA (i.e., perceived and objective health-related) would be remiss without considering the different domains of job demands, and WA. Specifically, WA has been thought to include physical, mental, and social/interpersonal abilities to meet the demands of particular jobs. In other words, the importance of each domain in determining WA depends on the importance of that particular ability to perform their work effectively. This is also explicitly considered within the scoring of the WAI, which weights mental and physical WA according to the demands of the occupation. However, we do not necessarily view objective health-related WA or perceived WA to be more important in this regard. Rather, the relative importance of WA likely depends the job demands, as well as the WA domain (e.g., physical, mental), and the type of WA being assessed (objective health-related or perceived). In this way, the WA literature is analogous to job fit and overqualification research, where objective and subjective aspects of the construct need to be disentangled in order to advance the literature, and we suggest future research be conducted to 
more clearly delineate between the aspects of WA and the importance of WA relative to the demands of specific jobs.

Conceptual distinction between WA and existing constructs. There is also a lack of conceptual clarity between WA and several existing psychological constructs. In other words, we lack understanding of WA's nomological network compared to work-related psychological constructs such as person-job fit, self-efficacy, employability, organizational-based self-esteem, and subjective aging. For example, WA refers to a person's ability, or perceptions of their ability, to meet the demands of their job, which is conceptually similar to the construct of personjob fit, or the degree of alignment of one's personal characteristics (i.e., values, personality) with job demands. We would posit that perceived WA and P-J fit are likely more strongly related than objective health-related WA and P-J fit. However, we also argue that the relationship between these constructs depends on how WA and P-J fit are measured. For instance, objective healthrelated indicators of WA may provide different information about one's ability to meet job demands compared to P-J fit, and thus could provide incremental validity. Although we expect that perceived P-J fit and perceived WA would overlap more there are also notable differences between the two indicating each may explain unique variance in important outcomes. For example, perceived WA often takes into consideration one's current ability relative to their lifetime best, or one's assessment of their projected WA two years in the future, which are comparative assessments of one's current of future ability that are not considered in P-J fit measures. These comparative assessments may indeed be strong critical components to the links between WA and exit from the workforce. To our knowledge, no studies have examined the relationship between P-J fit and WA, and future research needs to explore the relationships and distinctions between these constructs. 
In addition, WA has conceptual similarities to both job and general self-efficacy, in the sense that perceptions of one's ability to meet job demands (i.e., perceived WA) could overlap with one's belief in their agency to be successful in a variety of situations (general self-efficacy) and to be successful in a particular job (job self-efficacy). McGonagle and colleagues (2015) provide some evidence of a distinction between perceived work ability and both general and job self-efficacy. For instance the researchers found that general self-efficacy was related to both perceived WA and the WAI in a similar manner $(r=.40, r=.45)$, whereas the relationship between perceived WA and job self-efficacy $(r=.42)$ appeared to be stronger than the relationship between the WAI and job self-efficacy $(r=.29)$. Although these concepts are similar to WA, as noted above, measures of perceived WA often incorporate internal comparisons between one's previous and future ability (e.g., ratings of your current WA compared to your lifetime best, and your expected WA in two years). These aspects of perceived WA are largely untapped in other established constructs, and likely provide unique information beyond related measures.

Although research examining the conceptual distinction between WA and similar established constructs is limited, McGonagle and colleagues (2015) have investigated the convergent and discriminant validity of perceived work ability and found support for the distinctiveness of perceived work ability. For instance, the researchers found support for the convergent validity of perceived work ability by observing a significant positive relationship with the WAI. Further, they found evidence of discriminant validity between perceived work ability and conceptually overlapping variables such as employability, general self-efficacy, job self-efficacy, and disability. 
A second possible way to address this issue is the assessment of WA from a more comprehensive approach. For example, Ilmarinen and colleagues (2015) developed and validated a multi-dimensional 18-item measure of WA, termed the Work Ability - Personal Radar (WAPR). The WA-PR assesses five factors including work factors, attitudes and motivation, competence, health and functional capacity, as well as non-work activities (Ilmarinen et al., 2015). Ilmarinen and colleagues (2015) psychometrically assessed the WA-PR's construct validity through examining its factor structure, invariance across groups (gender, age, and type of employee), and its convergence with alternative measures of WA. The authors found a multifactor structure of WA (five factors) fit the data the best, measurement invariance across gender, and a significant, positive relationship with alternative measures of WA. Voltmer and Deller (2018) followed a similar multi-factor investigation of WA with their introduction of the Work Ability Survey (WAS-R). The WAS-R assesses personal and organizational capacity on nine subscales, which they argue reduces variation between individuals by adding factors beyond physical health. Voltmer and Deller (2018) found that the multi-factor WAS-R model had acceptable fit with the data in two samples and had acceptable internal reliability and convergent validity with the WAI as well as other expected variables (i.e., sickness absence, physical health, psychological well-being). However, although measures such as the WA-PR and the WAS-R show promise as ways to conceptualize WA from a multi-factor perspective, they may lead to even more conceptual and measurement confusion, as they include items similar to existing job characteristics measures (i.e., supervisor support). Therefore, more research is needed to assess the discriminant and incremental validity of each of these new WA measures to advance our understanding and provide more clarity of the nomological network of WA.

\section{Summary of WA Operationalization}


In summary, we identified three overarching issues involving the construct of WA. First, the measurement of WA is quite varied. Second, the conceptual and theoretical foundation for WA has been largely ignored. And third, the construct validity of WA continues to be relatively understudied. From our discussion of the measurement of WA, we observed that there was a lack of a clear theoretical articulation of the construct's definition and content domain because it was originally developed atheoretically. Further, the proliferation of WA measures is likely a result of the diversity of disciplines investigating WA, which can limit the comparability of results (see Lederer, Loisel, Rivard, \& Champagne, 2014) for a comprehensive discussion of the different levels and dimensions of work ability and work disability). Our discussion of WA measurement identified a clear trend to reduce the number of items used to assess WA, and a marked shift to focus strictly on perceived WA and remove objective indicators of WA.

These issues all raise fundamental questions about the conceptual distinction of these constructs that need to be answered in order to provide the conceptual and measurement clarity required to advance the WA literature. First, can we rely on the perceived WA construct to adequately measure WA based on the original definition? Second, how does the removal of objective health-related WA influence the validity of the construct within the broader nomological network? In other words, what is the impact on the construct validity and predictive utility of WA when we shift from assessing both objective and perceived WA indicators to strictly focusing on perceived WA, particularly for outcomes of greatest interest to IO researchers?

Recent research by McGonagle and colleagues (2015), Ilmarinen et al (2015), and Voltmer and Deller (2018) provides a start for investigating and approaching these concerns with operationalization and conceptualization of WA. First, these researchers recognize the need for 
construct clarity, but they diverge in their approaches to reaching such clarity in that one team of researchers rooted their measure in an established theoretical foundation (i.e., job demands resources model; McGonagle et al., 2015) while the other teams of researchers utilized a less theoretical and more model-based conceptual framing (i.e., "house model” of work ability; Ilmarinen et al., 2015; Voltmer \& Deller 2018). Second, the theoretical integration established a framework by which one could approach future investigations of the nomological network for the antecedents and outcomes of WA as would be suggested by their respective models. Third, these researchers examined multiple facets of their respective measure's construct validity such as factor structure and convergent and discriminant validity. Future research focused on advancing WA in terms of measurement and conceptual clarity should look to these papers as a guide for addressing the questions we have posed regarding the need for conceptual clarity and construct validity of WA.

\section{Moving the Field Forward: Grounding Work Ability in Established Organizational Theory}

\section{Early Models of Work Ability}

As we pointed out above, the confusing operationalization and measurement of WA most likely stems from the fact that it was not created within a particular theoretical framework. Initially, WA was conceived as a health-based concept, focused solely on whether or not the employee has the physical and mental resources to meet the demands of their job. However, over time, there has been a shift toward a more holistic and versatile view of WA, which recognizes that WA is affected and promoted by a variety of factors (Ilmarinen, 2009). In the holistic model, WA is depicted as a work ability "house". An individual's resources (health and functional capacities, knowledge and skill, and values, attitudes, and motivation) form the "foundation" of the house (first three floors), followed by "work" which includes the conditions, content, and demands of work (the fourth floor). WA is represented by the roof of the house, which balances 
on the foundation of the work and individual resource floors. Finally, the WA house is also affected by its proximal (e.g., family), and distal (e.g., society) environment.

Although the holistic model is an appealing way to describe WA in an interpretable manner, it currently lacks integration with existing theories of the workplace and aging and remains largely untested empirically. For example, the depiction of floors indicates that there may be a hierarchy of variables in relation to WA but there is a lack of empirical research examining this hierarchy. In addition, investigation of how the floors may interact with each other as well as with their 'surroundings' is deficient. Therefore, the holistic model of WA is in need of systematic research scrutiny to establish it as a valid theory of WA within the psychology literature.

\section{Advancing Work Ability Theory}

We propose that an alternative way to advance the theoretical discussion of WA in the organizational psychology literature is not to create a new theory or model specifically for the concept of WA, but rather utilize existing theories to ground the concept of WA. For instance, even though WA's development focused on how to retain and maintain an aging workforce, it fails to integrate lifespan development theories that have influenced psychological approaches to work. Likewise, current conceptualizations do not adequately utilize organizational psychology theories. In this section, we advance the theoretical discussion of WA by integrating WA into the lifespan development theory of selective optimization and compensation (Baltes \& Baltes, 1990) as well as into the job demands-resources model (Demerouti et al., 2001).

We begin this discussion by referring back to our discussion of the conceptual distinction regarding objective and perceived WA. Specifically, we argue that there are two distinct processes involved with the work ability construct. First, there is the biological/physiological 
aspects of work ability (i.e., objective health-related WA) which may best align with the lifespan development theories. Second, there are the psychological aspects of work ability (i.e., perceived WA) which best align with the JD-R model in the sense that perception is based on personal, situational, and contextual aspects that influence this type of WA and may be best captured by job demands and job resources as conceptualized in the JD-R model.

\section{Work Ability and Theories of Lifespan Development}

Despite the fact that WA is related to age-related biological and physiological changes that occur through the lifespan, its logical integration with lifespan development theories is lacking. The lifespan development perspective presents aging as a process of changes (e.g., physical, cognitive, emotional) across the lifespan requiring individual adaptation. Lifespan theory also recognizes that these changes may include both gains and losses (Baltes, 1987). Therefore, there seems a logical overlap between the principles associated with lifespan development and WA, but investigation of WA from a lifespan development perspective is relatively sparse (see Müller, Weigl, Heiden, Glaser, \& Angerer, 2012; Müller et al., 2013; Müller et al., 2016; Riedel, Müller, \& Ebener, 2015; von Bonsdorff et al., 2014 for recent exceptions).

We see multiple opportunities for integration between WA and lifespan development theories. However, we will limit our discussion two dominant theories. First, SOC theory (Baltes \& Baltes, 1990) describes how people adjust to physical and mental declines by selecting to focus on optimized skills and abilities to compensate for losses. Selection is the decision-making strategy about which goals to prioritize and pursue based on matching personal resources with demands. Optimization is the process of obtaining, improving, and coordinating the use of personal resources to meet the selected goals. Compensation is the attainment and application of 
alternative means or the utilization of external aids to substitute for age-related losses (Müller \& Weigl, 2015). Given that WA is intended to capture one's ability to meet the demands of their job, there seems to be a natural dynamic relationship between WA and SOC strategy implementation when there is a misalignment of an individual's ability and job demands over the lifespan. In other words, age-related developmental changes will trigger misalignment of ability and demand, and thus an individual's effectiveness in implementing the adaptive strategies of SOC could explain differences in WA across the lifespan. Further, objective changes in WA may trigger these adaptive behaviors earlier, whereas changes in contextual factors (job demands and resources), may influence perceived WA more slowly as they are more subject to interpretation. Thus, people who effectively implement these strategies over the lifespan could experience greater WA or would better maintain their WA throughout their work lives.

Second, SST (Carstensen et al., 1999) describes how individuals assess their remaining time, which influences the selection of social goals (i.e., knowledge acquisition, emotion regulation). Because older people perceive relatively little time remaining, they focus on close interpersonal relationships whereas younger people who have a more expansive perspective of time remaining will select social goals related to knowledge acquisition. SST could provide an explanation as to why certain interventions could be more effective depending on where a person is in their lifespan. For instance, job resources such as coworker and supervisor support could be stronger predictors of perceived WA for older workers versus younger workers.

In summary, both theories seem ripe for integration with the WA literature, given that WA focuses on an individual's assessment of their current and future resources and abilities and how well these fit their current job. As such, integrating WA with these theories should add to a greater understanding of what WA is, its relationship with a person's adjustment to age-related 
losses, as well as its antecedents and outcomes. We created Figure 1 as a conceptual depiction of how both SOC and SST may be integrated with WA. We recognize that there could be a bidirectional relationship between the lifespan development adaptive processes and objective and perceived WA. For example, low perceived WA could trigger compensatory behaviors and high utilization of compensatory behaviors could influence perceived WA.

\section{Integrating Work Ability Using the Job Demands-Resources Model}

Although the initial WA models were helpful for identifying different individual and contextual factors related to WA, the fact that they were largely atheoretical has made it difficult to identify the mechanisms through which WA can be improved. Based on our previous discussion of the conceptual distinction between objective and perceived WA, in this section, we explain how the JD-R model, initially used to examine WA by McGonagle and colleagues (2014), may be a useful theoretical framework for studying WA, and in particular, perceived WA. In other words, perceived WA may generally be more influenced by job demands and job resources than objective WA. Below, we summarize the JD-R model, and how it is used to understand the various factors affecting individuals' WA. In our conceptual model (Figure 1) we have placed job demands and resources as influencing the lifespan development adaptation mechanisms, objective and perceived WA, and the four categories of outcomes. We feel that job demands and resources could have both direct and indirect relationships with objective and perceived WA and the outcomes through enhancing or constraining the use of lifespan adaptive behaviors to then influence work ability and the outcomes.

Job Demands-Resources Model. According to the JD-R model, although every occupation has its own specific risk factors associated with job stress, all working conditions can be classified in one of two general categories: job demands and job resources (Bakker \& 
Demerouti, 2007; Demerouti et al., 2001). Job demands (e.g., physical demands, time pressure) require effort and can elicit strain, (i.e., health impairment pathway) whereas job resources (e.g., support) facilitate goal achievement or reduce job demands (i.e., the motivation pathway; Bakker \& Demerouti, 2007). In addition to these job focused demands and resources, recent extensions to the JD-R model have included personal resources, such as general self-efficacy as important individual factors to consider (Bakker \& Demerouti, 2007).

WA and the JD-R. Because WA is conceptualized as a balance between one's resources and work demands (Ilmarinen, 2009) WA fits logically into the JD-R model. Conceptually, the JD-R framework also provides alignment with regard to objective and perceived WA. For instance, objective WA is related to physical health indicators, which seems to align with the health impairment pathway of job demands, whereas perceived WA is potentially more related with one's interpretation of their environment in comparison to their capabilities and therefore could be better aligned with job resources and the motivation pathway. In Figure 1, we have inserted differently dashed rectangles to reflect the hypothesized alignment between the motivational and health impairment pathways with their respective type of WA and outcomes. It is also beneficial to utilize the JD-R because of its flexibility and widespread applicability. One of the main advantages of the JD-R model is that it can take into account the different demands and resources present in various occupations and roles. This is important, as WA is a relevant construct for all employees, regardless of the nature of their work, and one that can vary depending on the interface between the individual and their job.

McGonagle and colleagues (2015), Airila and colleagues (2014), and Weigl and colleagues (2013) have utilized the JD-R model in developing their hypothesis in their respective investigations of WA. Airila and colleague's (2014) research provides support for perceived 
WA's relationship to the JD-R's motivational pathway in that they found a significant indirect relationship between perceived WA and perceived WA 10 years later through work engagement (a motivational pathway outcome). Weigl et al (2013) argued that according to the concept of WA (e.g., Ilmarinen, 2009), contextual features of work prospectively influence employees' WA, which is in accordance with the JD-R model. Although some of the specific job demands and job resources examined by McGonagle and colleagues (2015) were not found to be predictive of WA these studies built an important foundation for the study of WA within the IO literature. It underscored the need for organizational scientists to improve the understanding of the WA construct through integration with psychological and organizational theory. Second, it demonstrated that the application of the JD-R model for understanding WA is theoretically sound, as the authors did find that unfavorable body positions and time pressure (job demands) and autonomy (a job resource) were related to perceived work ability.

In sum, the integration of the JD-R model as a theoretical foundation of WA seems promising, but further investigation is needed to explore additional job demands and resources as well as whether differential relationships exist when looking at objective and perceived WA. A major advantage of using the JD-R model is that it is broad and comprehensive enough to incorporate all aspects of previous WA models and conceptualizations. For example, the "house" model's constructs of health and functional capacities; competence; values, attitudes, and motivation; and work, work community and leadership, can all be broken down into factors that act as "demands" versus "resources" as they relate to WA.

\section{Review: What Do We Know about the Antecedents and Outcomes of WA?}

Having reviewed the development of the WA concept from both an operational and theoretical perspective, as well as lifespan development and stress models that could be used to 
better understand WA, we move into our qualitative review of the extant WA literature. Here we briefly describe the process used to identify the WA articles considered for this review. First, we started our literature search of the PsycINFO and PubMed databases using the terms "Work Ability", "Work Ability Index", "Work Ability Assessment”, and related search terms. We restricted the results to articles published after 1980 (when the WA concept was established), and up to June 2017. We further restricted our search to articles that conceptualized WA in line with the definition provided by Ilmarinen and colleagues (1997). This resulted in over 600 total articles for consideration for our review.

Given the large quantity of articles and the breadth of the WA literature, we pared down the literature by applying additional restrictions. First, the paper needed to be written in English. Second, because we wanted to provide a summary of results that could be more generalizable, we decided to focus our attention on articles that included employed participants. Therefore, research on unemployed individuals (i.e., on long-term disability, involved in a return to work process) or on a patient population recovering from an illness (i.e., cancer patients, surgery patients, and transplant patients) were not considered in our review. Third, articles primarily focused on construct validation of WA in a different language were not considered in this review.

WA has been treated both as a predictor and an outcome. We begin by using the JD-R as a framework to organize the antecedents of WA. We categorize the antecedents of WA through this JD-R lens by designating them as job demands, job resources (structural and relational), and personal resources (e.g., personality). Additionally, we discuss how the lifespan theories SOC and SST may provide an explanation some of the results or may serve to guide future research investigating the antecedents of WA. Subsequent to the predictors of WA sections, we briefly 
review the findings from a smaller body of research examining WA as an antecedent of other outcomes. We will conclude this section with a synthesis of the literature examining interventions focused on improving or maintaining WA.

\section{Antecedents of WA (WA as an Outcome)}

The JD-R identifies several categories of demands and resources including job demands, structural resources, relational resources, and personal resources. The purpose of this section is to summarize the research that has positioned these constructs as antecedents of WA. To aid our synthesis of the literature, we have sorted the research findings into these categories. We note that some of these antecedent constructs could also be viewed as outcomes of WA. However, it can be difficult to the determine causality of these relationships because many studies of WA have not utilized longitudinal or experimental designs. Further, some of these relationships are likely bi-directional. Such an example is health, which can be viewed as a key risk factor for developing poor WA, while poor WA can also lead to further health impairments.

Job demands. Job demands refer to "physical, psychological, social, or organizational aspects of the job that require sustained physical and/or psychological (cognitive and emotional) effort or skills and are therefore associated with certain physiological and/or psychological costs" (Bakker \& Demerouti, 2007, p. 312). Examples of job demands include high work pressure, emotionally demanding work, and unfavorable working conditions. Job demands are not necessarily detrimental, but they may be perceived as stressful and lead to strain if the employee has not recovered from previous effort expenditure (Meijman \& Mulder, 1998) or does not have the resources to meet those job demands. Theoretically, the potential strain elicited by job demands can have a negative impact on WA, and WA researchers have examined a variety of job demands and their relationship with WA. 
Physical demands. Physical demands are one of the most frequently investigated job demands empirically associated with WA. Research has operationalized this concept in various ways ranging from broad "physical demands" (e.g., Tuomi et al., 1991; Habibi, Dehghan, Zeinodini, Yousefi, \& Hasanzadeh 2012), physical workload (Costa \& Sartori, 2007) or physical work environment (e.g., Hakanen, Bakker, \& Schaufeli, 2006) to more specific descriptions such as unfavorable body positions (e.g., McGonagle et al 2015). As expected, the common theme across these studies is that there is a negative relationship between physical job demands and WA when using either objective or perceived measures of WA. Van den Berg and colleagues (2008) found a similar trend in their review, finding that high physical demands were associated with lower WA. This result not only matches expectations with regard the JD-R model, but also aligns with lifespan development theory focused on physical aging where physical demands would affect one's ability to work because of experienced reductions of physical capacity as a result of the aging process. An important question for future research is whether objective physical demands have a stronger relationship with objective WA and whether perceived physical demands have a stronger relationship with perceived WA. Additionally, the role of how job type (i.e., laborer versus office worker) could influence the relative importance of physical demands with regard to a person's WA is a question that remains and should be further explored.

Mental demands. A second type of job demand is broad mental demands (e.g., van den Berg et al., 2008), which also includes cognitive demands (e.g., Mache, Danzer, Klapp, \& Groneberg, 2013), quantitative demands (Mache et al., 2013; Riedel et al., 2015), and mental workload (van Holland, Soer, de Boer, Reneman, \& Brouwer, 2015). The results investigating the relationship between mental job demands and WA are mixed. Several researchers have found a negative relationship between mental demands and WA (e.g., Pranjić, Maleš-Bilić, Beganlić, \& 
Mustajbegović, 2006; Tuomi et al., 1991; Tuomi et al., 1997; Tuomi, Huuhtanen, Nykyri, \& Ilmarinen, 2001). In addition, Karttunen and Rautiainen (2011) found that a lack of mental breaks resulted in lower WA, as measured by the WAI. In contrast, there is research that has found no significant relationship with mental demands and the WAI (e.g., Mache et al., 2013). Mache and colleagues (2013) did not find a significant relationship between cognitive demands and WA when they entered personal resources, job resources, and other job demands in the same regression analysis. Likewise, van Holland and colleagues (2015) used the WAI and did not find a significant relationship between mental workload and WA in a sample of employees working for a meat processing company. One explanation for the inconsistent results could simply be the type of job that the participant is performing. Different jobs have varying levels of mental workload, which would influence how important mental demands are in relation to WA. Another explanation is the inconsistent operationalization of mental job demands, which may lead to vastly different constructs being labeled mental demands (e.g., knowledge requirements, vs working at a fast mental pace), and ultimately to different relationships between WA and these different forms of mental demands. Moreover, perhaps some of the mental demands are perceived as a challenge in a positive sense (e.g., utilizing a variety of knowledge) whereas others are perceived as being a hindrance such as dealing with aspects of work that are entirely unhelpful in performing job duties.

Because mental and physical health could have intra-individual variation through the lifespan, this could reduce or enhance an effect depending on how strongly correlated these items are. In any case, the inconsistent results warrant further investigation of the relationship between mental demands and WA. Specifically, a key research question is whether actual age-related cognitive changes influence actual WA more than perceived WA. Another question is whether 
the mixed results found for the relationship between mental demands and WA is because lifespan cognitive gains (i.e., gains in crystallized intelligence) offset fluid ability losses in certain circumstances (i.e., different jobs). In other words, SOC theory may explain how an individual utilizes gains in crystallized intelligence to compensate for lifespan losses in fluid intelligence.

Psychosocial demands. Psychosocial demands have been discussed and operationalized in multiple ways, including poorly organized work (Ilmarinen et al., 1991a), experienced mobbing behavior (i.e., Pranjic et al., 2006), role overload (i.e., McGonagle et al., 2015), role conflict (e.g., Ilmarinen et al., 1991a; McGonagle et al., 2015), role ambiguity (i.e., Tuomi et al., 1997), and time pressure (i.e., McGonagle et al., 2015, Müller et al., 2013). In their summary of multiple studies conducted with Finnish municipal workers using the WAI, Ilmarinen and colleagues (1991b) identified several psychosocial demands related to reduced WA, which included role conflicts, fear of failure and mistake, time pressure, among others that they categorized as poorly organized work. McGonagle and colleagues (2015) found mixed results regarding time pressure and perceived work ability across their three samples. In their first two samples, there was a non-significant positive relationship with perceived work ability, and in the third sample there was a significant negative relationship at Time 1 and a non-significant negative relationship at Time 2 . The mixed results indicate the relationship between psychosocial demands and WA may be moderated by whether we are investigating perceived or actual WA and as well as personal and situational factors and needs further exploration. For example, from a SOC perspective, time pressure demands could be more closely associated with objective WA because time pressure demands may require more fluid intelligence resources, which are impacted by age-related declines over time and may elicit selection, optimization, and compensatory adaptive resource in response, which could be more related to objective resources 
rather than perceived resources. We also feel the role of how job type could influence the relative importance of psychosocial demands with regard to a person's WA needs more investigation in the future.

Emotional demands. There has been limited research examining emotional demands as a potential antecedent of WA. Arguably, emotion-related workplace demands such as emotional labor result in strain (McGonagle et al., 2015), which could lead to reduced WA. Hakanen and colleagues (2006) found support for a negative relationship between pupil misbehavior and perceived WA in a sample of teachers. Likewise, Fischer and colleagues (2006) found a significant relationship between verbal abuses (more than 2 times in the last 12 months) and lower WAI. However, McGonagle and colleagues (2015) did not find a significant relationship between conflictual contact and perceived WA. Similarly, Mache and colleagues (2013) did not find a significant relationship between emotional demands and demands for hiding emotions in a sample of surgeons. From a SOC perspective, the lack of a significant relationship could reflect the compensatory or buffering effect of age-related gains in socioemotional regulation observed over the lifespan (Charles, 2010), in that older workers are better equipped to deal with emotional demands. Therefore, these personal resource gains could buffer the negative impact of emotional demands and result in these demands having relatively little impact on WA.

Emotional demands outside of work such as caregiving for one's children, spouse, or parents could result in compromised WA. Fischer and colleagues (2009) found that currently raising children was related to lower levels on the WAI. Similarly, Vedovato and Monteiro (2014) found a negative relationship between having children and the WAI. However, a promising study conducted by Fuß and colleagues (2008) found low levels of work-to-family interference was related to increased scores on the WAI. Overall, there have been mixed results 
regarding the relationship between emotional demands and WA. More research is needed to fully examine the relationship between emotional job demands and WA and whether this relationship depends on whether you examine perceived versus actual work ability. From a SST perspective, valuing social goals over knowledge acquisition later in life may lead to emotional demands being viewed more favorably than at earlier points in one's life. In addition, some types of jobs may have more emotional demands (i.e., customer service), and therefore may have relative importance with regard to a person's WA and this needs more future research investigation.

Work conditions. A final category of job demands can be broadly discussed as negative working conditions such as job-related exposures to harmful aspects of the work environment. For example, working in extreme cold (e.g., Sormunen, Remes, Hassi, Pienimaki, \& Rintamaki, 2009) was associated with lower WA. Fischer et al. (2006) found that frequently feeling thermal discomfort was related to lower WA. Tuomi and colleagues (2001) reported a significant negative relationship between poor work tools and rooms as well as poor physical climate and WAI. Similarly, understaffing was related to lower WAI in a sample of Brazilian nurses (Vasconcelos, Fischer, Reis, \& Moreno, 2011). The negative results related to the physical climate are not unexpected given that adjustment to these conditions requires physical energy, which would leave individual resources depleted, thus reducing a person's WA. In fact, using SOC theory we would anticipate that lifespan losses in the ability to maintain homeostasis (McDonald, 1988) would leave older workers even more susceptible to the negative impact of working conditions, which would trigger more selection, optimization, and compensation behaviors. This is a relationship that needs further investigation especially if there could be differential effects on objective and perceived WA. 
The impact of shiftwork on WA has garnered considerable research attention as a negative working condition in its relation to WA, but the results have been mixed. Some research has shown support for a significant negative relationship between shift work and WA (e.g., Costa \& Sartori, 2007; Elovainio, Kuusio, Aalto, Safari, Akbari, Kazemi, Mououdi, \& Mahaki, 2013; Sinervo, \& Heponiemi, 2010). Additionally, night shift work has been found to be negatively related to WA in nurses working as temporary employees (Rotenberg, Griep, Fischer, Fonseca, \& Landsbergis, 2009). However, others have not found shift work to have a significant effect (e.g., Fischer et al., 2006; Sorić, Golubić, Milošević, Juras, \& Mustajbegović, 2013; Yong et al., 2010). Fischer and colleagues (2006) did not find a significant relationship between shift work and WA after controlling for socio-demographic variables but WA was dichotomized as inadequate versus adequate in the study. Similarly, Yong and colleagues (2010) did not find a significant relationship between rotating 12-hour shifts and the WAI. Interestingly, Galatsch and colleagues (2013) found that when a nurse's request for a schedule change was approved it resulted in greater scores on the WAI whereas when a nurse was forced into a schedule change it resulted in decreased WAI. Overall, poor working conditions seem to be associated with lower WA except for the mixed results observed when examining shift work.

\section{Job Resources}

Job resources refer to physical, psychological, social, or organizational aspects of the job that are functional in achieving work goals, reduce job demands and the associated physiological and psychological costs, or stimulate personal growth, learning, and development (Bakker \& Demerouti, 2007). Job resources can be present at different levels of the work environment and come from various sources at the organizational, interpersonal, and work levels. Theoretically, job resources should positively influence WA in that they can facilitate effective utilization of 
selection, optimization, and compensation behaviors resulting in successful work goal achievement and effectively meeting job demands.

Structural job resources. Structural resources are aspects of the job or organization that that enrich and/or facilitate the achievement of work goals or buffer the negative impact of job demands (Ellis et al., 2015; McGonagle et al., 2015).

Job control. Job control refers to the level of discretion an individual has over their job responsibilities. Using SST as their theoretical guide, Ng and Feldman (2015) meta-analytically investigated how age influences the relationship between job autonomy (a type of control) and several work outcomes. They found that the relationship between job autonomy and job selfefficacy and job performance was stronger for older workers, while the relationship between job autonomy and job satisfaction and affective commitment was weaker for older adults. These results indicate partial support for SST to explain the observed relationships in that job autonomy seems to allow older workers to choose to seek out the positive work experiences they value, but it also partially supports the idea that autonomy allows younger workers to pursue their drive for knowledge acquisition resulting in more positive job attitudes in comparison to their older counterparts.

In WA research, job control has been generally rooted in Karasek's (1979) job demands control model which proposes that the level of work-related strain depends on the level of job demands and the individual's level of control. Job control is operationalized in many ways including job authority, decision latitude, skill discretion, job autonomy, and opportunities to influence. Job control is one of the most frequently studied job resources in connection with WA. Conceptually, job control allows the individual the freedom to decide how best to match their current resources to current demands, and thus should have a positive impact on WA (objective 
and perceived). In other words, individuals who have control are able to best implement adaptive behaviors such as selection, optimization, and compensation in order to address job demands. Research shows consistent support of a positive relationship between all aspects of job control and both perceived and objective WA (e.g., McGonagle et al., 2015; Müller et al., 2012; Angerer, 2012; Riedel et al., 2015; Tuomi et al., 1997; van den Berg et al., 2011; Weigl et al., 2013). In other words, job control is a job resource that is associated with increased levels of WA, while lack of control results in reduced WA regardless of whether it is operationalized as perceived or objective WA. Moreover, this robust relationship seems to hold across research designs (i.e., cross-sectional, longitudinal), jobs, industries, and national context.

Fairness. The idea of fairness is reflected by the concept of effort-reward imbalance as well as organizational justice, both of which have garnered research attention as antecedents of WA. The effort-reward imbalance (ERI) model was developed by Siegrist (1996) and posits that the positive impact of work on individuals is dependent on whether the individual feels there is a fair exchange of rewards for effort. Conversely, a lack of alignment between rewards and effort leads to emotional strain and negative health. Several studies have examined the relationship between ERI and WA (e.g., Bethge \& Radoschewski, 2010; Bethge, Radoschewski, \& Gutenbrunner, 2012; Fischer \& Martinez, 2013; Fischer \& Martinez, 2011). Research supports a reliably negative relationship between ERI and WA, indicating that the larger the imbalance between effort and reward, the more detrimental the impact on WA. Similar to job control, the relationship is consistent across research designs (i.e., cross-sectional, longitudinal), jobs, industries, and national context. The ERI research on WA would benefit from an investigation of whether there is a difference in the impact of imbalance on perceived versus objective WA. We would expect that because effort and reward are based on perceptions, ERI would be more 
strongly related to perceived WA. In addition, organizational justice has garnered attention as an antecedent of WA. Elovainio and colleagues (2010) did not find an effect for perceived justice by supervisors on WA, whereas von Bonsdorff and colleagues (2014) found a positive relationship between organizational justice and WA.

Opportunity for development. Providing employees opportunities to develop and maintain their knowledge, skills, and abilities has been examined as a job resource that could impact WA (e.g., Tuomi et al., 1991; Tuomi et al., 1997; Tuomi et al., 2001). Tuomi and colleagues (1991, 1997, 2001, 2004) found a significant positive relationship between an employee's opportunity to develop and WA, which provides promising support for this job resource as a way to develop and maintain objective and perceived WA. From SOC theory, we would expect that the opportunity to develop would help build resources that could be used from an optimization and compensation standpoint. Moreover, if the opportunities to develop included a social component like mentoring others, it could particularly beneficial to older workers given that generativity motives increase over the lifespan (Kanfer \& Ackerman, 2004), which aligns with SST.

Organizational climate and culture. The existence of a positive organizational climate and culture has also been examined in relation to WA. Theoretically, from an SOC perspective we would expect that a positive organizational climate and culture would allow for individuals to select and adapt in order to better fit with current demands leading to increased levels of WA. Moreover, from an SST perspective, positive cultures and climates could potentially facilitate a better environment for individuals to pursue their increased motivation to build and maintain positive relationships resulting in higher levels of WA. For example, Feldt and colleagues (2009) found that employees who had a consistently excellent WA in their 10-year study gave their 
organization's climate the highest rating. Additionally, Larsson and colleagues (2012) found that safety climate related to higher WA in a sample of care aides. Palermo and colleagues (2013) found that organizational nurturance culture was indirectly related to WA through job satisfaction. Finally, longitudinal research has found that an increase in organizational promotion of employee well-being results in higher WA (Tuomi, Vanhala, Nykyri, \& Janhonen, 2004). The research examining the relationship between organizational climate and culture and WA is relatively sparse despite the fact that they seem to be related to WA. Future research should examine different organizational cultures and how they could affect perceived and objective WA. For example, a culture focused on maintaining employee healthy lifestyles in and outside of work could be a resource that could dramatically impact both objective and perceived WA.

Job security. Job security or one's perception that there is high likelihood of maintaining employment is another job resource investigated as a predictor of WA. The limited studies examining this construct are from a job insecurity perspective and these studies support the negative impact of job insecurity on WA (i.e., Elovainio et al., 2010; Mazloumi, Rostamabadi, Saraji, \& Foroushani, 2012; Rotenberg et al., 2009). For example, Elovainio and colleagues (2010) found that nurses with an insecure work contract had lower perceived WA than those with a permanent contract. In addition, Rotenberg and colleagues (2009), using the WAI, found that people in precarious employment situations had lower WA. Given the dearth of research on job security and WA, it would be useful to investigate job security as a resource that supports WA. On the other hand, it could be that job security is expected but when there is a lack of security it has a significant impact on WA. In addition, we anticipate that perceived job security could be particularly important for perceived rather than objective WA. From an SST perspective, having fewer concerns about job security could allow workers to focus on building 
and maintain strong social workplace relationships. This might include mentoring newer employees, which becomes increasingly important as one's perceived time remaining declines.

Other structural job resources. There are additional structural job resources that have seen limited research in the WA literature but that could be promising future avenues of research. One example is the use of knowledge or experience, which has seen limited research as a predictor of WA. Tuomi and colleagues (2001) found a positive relationship between utilization of work experience and WA. Based on SOC, we would expect that this would have a significant impact on the perceived WA of older workers given that crystallized intelligence is an agerelated cognitive gain that can be utilized as a compensatory behavior, and when leveraged could result in increased perceptions that one can meet their current job demands across the lifespan.

Relational job resources. Relational resources are aspects of the social environment that support the achievement of work goals or buffer against the negative impact of job demands (Ellis et al., 2015; McGonagle et al., 2015). Workplace social support is the perceived or actual assistance received from other individuals at work. Some research has investigated social support more broadly (e.g., Fischer \& Martinez, 2013; Han, Shi, Lu, \& Ling 2014; Kaewboonchoo, Saleekul, \& Usathaporn, 2011; Mache et al., 2013) whereas other research has examined specific sources of support, such as coworkers (e.g., Koolhaas, van der Klink, de Boer, Groothoff, \& Brouwer, 2014; Mazloumi et al., 2012; McGonagle et al., 2015), supervisors (e.g., Ghaddar, Ronda, \& Nolasco, 2011; Mazloumi et al., 2012; McGonagle et al., 2015, Sugimura \& Theriault, 2010), and organizations (Koolhaas et al., 2014). Much of the research examining social support has found a significant positive relationship between social support and WA. However, Koolhaas and colleagues (2014) did not find a significant relationship between coworker and supervisor support and WA, but they did find a significant positive relationship 
between community support and WA. One unaddressed question that may be informed by the lifespan development theory SST is, do older individuals in particular benefit more from increased support as their social and relational motives become stronger? Based on SST, it seems that older individuals may benefit more from these forms of support, and perhaps increasing the opportunities for older workers to provide support (e.g., mentoring) would be particularly useful in promoting WA among older workers.

Personal resources. Personal resources are individual characteristics that facilitate the achievement of work goals or buffer the negative impact of job demands (Ellis et al., 2015; McGonagle et al., 2015). Initially, WA research focused on personal resources primarily focused on demographic characteristics, health-related status variables, and lifestyle behaviors. This research found that health, which is a component of the WAI, is strongly tied to perceived WA. Recently, more research has focused on the relationship between other personal resources such as personality, attitudes, and their relationship with WA (e.g., McGonagle et al., 2015). For example, conscientiousness, positive affectivity, and emotional stability were found to be positive related to perceived WA. Aside from the large body of research on health and WA, the impact of other personal resources, particularly personality-related individual differences, on WA remains understudied.

Demographic characteristics. Demographic characteristics refers to a broad category of individual characteristics such as age, gender, ethnicity, level of education, marriage status, number of dependents, and income. Researchers have generally found a fairly consistent, albeit small, negative relationship between chronological age and WA. The exceptions (e.g., Fischer et al., 2006) are most likely due to a skewed age distribution of relatively younger workers (van den Berg et al., 2008). Although the negative relationship between chronological age and perceived 
and objective WA would be expected because of the positive relationship between chronological age and disability (especially after the age of 50; Kampfe, Wadsworth, Mamboleo, \& Schonbrun, 2008). This relationship may be stronger for objective WA, an issue that should be disentangled in future research.

The research on gender and WA has observed mixed results, and these results may also be due to sampling artifacts (i.e., the relative distribution of gender in the sample) as well as to gendered job roles. Some research has shown that women tend to have lower WA (e.g., Bethge et al., 2012; Fischer \& Martinez, 2013; Rotenberg et al., 2009) whereas other research has shown no relationship (e.g., Padula, de Moraes, Chiavegato, \& Cabral, 2012; Tuomi et al., 2001), that women have higher WA (e.g., Lin et al., 2006), or differential relationship depending on age (e.g., Ilmarinen \& Tuomi, 1992) or jobs (Ilmarinen et al., 1997).

The relationship between level of education or years of education and WA is generally positive, indicating that those who complete more education generally have higher WA (e.g., Golubic, Milosevic, Knezevic, \& Mustajbegovic, 2009; Martinez \& Latorre, 2006). However, education level is likely a proxy for socioeconomic status and the type of work an individual is tasked with, where those with lower levels of education tend to work in more physically demanding jobs and those with higher levels of education tend to work more in mentally demanding jobs. Additionally, having dependents (i.e., children) has been observed to have a negative relationship with WA (Fischer et al., 2006; Vedovato \& Monteiro, 2014).

Job tenure, seniority, and professional tenure have also been examined as predictors of WA. Research has found mixed results between tenure and WA, with some research showing a positive relationship (i.e., Larsson et al., 2012; Mazloumi et al., 2012) and other research a negative relationship (i.e., Vedovato \& Monteiro, 2014). The mixed results are not surprising 
given the complex nature of tenure as a construct: It is related to chronological age, which is negatively related to WA, but it is also related to gained experience and skills, which should increase WA. Thus, the relationship may be curvilinear in that as younger and middle age workers gain skills and experience, their WA increases, but later in life as age-related declines occur, WA begins to decrease. This complicated relationship between tenure and WA deserves further study, as it may help to understand the many factors affecting WA.

Health status. Health status has been operationalized in many different ways in the WA literature from broad categories such as general health status (e.g., de souza Magnago et al 2012; Chiu et al., 2007; Koolhaas et al.,2014; Lindfors et al., 2007; Martinez \& Latorre, 2006; McGonagle et al., 2014; McGonagle et al., 2015; Pohjonen, 2001; van den Berg et al., 2008), mental health (e.g., Boschman, Van der Molen, Frings-Dresen, \& Sluiter, 2014; Kaewboonchoo et al., 2011; Ruitenburg, Frings-Dresen, \& Sluiter, 2012), and physical health (e.g., van den Berg et al., 2008). Broadly speaking, general health status, mental health, and physical health are positively related to WA. In other words, those who rate themselves as being relatively healthy (generally, mentally, and physically) have greater WA. The positive relationship between these health status variables and WA results should not be surprising given that the WAI includes items that capture diagnosed illness as well as mental and physical health status. This speaks to the conceptual overlap between WA and existing health measures and the need to investigate whether WA provides incremental validity beyond these measures especially when examining objective health outcomes.

Researchers have also studied how specific measures that serve as proxies for physical health such as pain and pain symptoms, BMI, and $\mathrm{VO}_{2}$ max are related to WA. Pain and pain symptoms are the most extensively investigated physical health antecedents of WA and research 
shows a consistent negative relationship between pain and WA (e.g., de Souza Magnago et al., 2012; Lindegård, Larsman, Hadzibajramovic, \& Ahlborg, 2014; Milani \& Monteiro, 2012; Monteiro, \& Alexandre, 2009; Neupane et al., 2013; Sell, Lund, Holtermann, \& Søgaard, 2014; Shiri et al., 2014; Phongamwong \& Deema, 2015). Significant negative relationships between weight-related measures (i.e., BMI, obesity) and WA have also been found (e.g., Fischer et al., 2006; Fischer \& Martinez, 2013; Kaleta, Makowiec-Dąbrowska, \& Jegier, 2006; Laitinen, Näyhä, \& Kujala, 2005; Yong et al., 2010). In contrast, research investigating $\mathrm{VO}_{2}$ max (i.e., maximal oxygen consumption) has found a positive relationship with WA (e.g., Pohjonen, 2001). Numerous other specific physical health symptoms have been examined (i.e., cardiorespiratory capacity, waist-to-hip ratio, muscular endurance, balance), but we will not provide a detailed discussion due to vast number of indicators investigated. However, the results examining these symptoms generally support that the greater levels of physical health indicated through these proxies result in higher WA regardless of how WA is operationalized.

Researchers have also investigated specific mental health variables as antecedents of WA and found significant negative relationships with depression (e.g., Shiri et al., 2013; Kaewboonchoo et al., 2011), burnout (e.g., Hakanen et al., 2006), exhaustion (e.g., Glise, Hadzibajramovic, Jonsdottir, \& Ahlborg, 2010), and anxiety (e.g., Walker, Jackson, Egan, \& Tonkin, 2015). The results indicate that mental health should be considered when examining WA. Drawing on the early development of WA, higher levels of mental health, and specifically the absence of depression and similar mental health ailments, likely increase an individual's ability to cope with the typical stressors experienced in a typical workday. Further, higher levels of mental health should allow individuals to allocate resources toward adaptive behaviors like selection, optimization, and compensation to maintain WA. Moreover, better mental health could 
also allow individuals to build and maintain health interpersonal relationships which aligns with increased social motivation as described in SST.

Lifestyle variables. Lifestyle variables generally refer to behaviors in people's daily lives outside of work. For example, research supports a positive relationship between physical activity outside of work and WA (Airila, Hakanen, Punakallio, Lusa, \& Luukkonen, 2012; Arvidson, Börjesson, Ahlborg, Lindegård, \& Jonsdottir, 2013; Jedryka-Góral et al., 2006; Pohjonene, 2001; Sormunen et al., 2009; Tuomi et al., 1991; Touomi et al., 1997; Tuomi et al., 2001). On the other hand, smoking tobacco is negatively related to WA (Tuomi et al., 1991; Tuomi et al., 2001). Alcohol consumption and WA has also been examined, however there has been mixed results for alcohol consumption, with some research finding a positive relationship (e.g., Karttunen \& Rautiainen, 2011; Tuomi et al., 2001) and other research observing no relationship (e.g., Airila et al., 2012; Tuomi et al., 1997; van Holland et al., 2015). Although a negative relationship would also be expected for heavy alcohol consumption, the frequency of reported heavy drinking by the participants in the studies was extremely low, which could explain why this relationship was not observed. However, these results provide some evidence that there may be a curvilinear relationship between alcohol consumption and WA where low-moderate alcohol consumption could actually be beneficial.

Research into the relationship between sleep and WA has been increasing lately, with a positive relationship generally found between sleep and WA (e.g., Airila et al., 2012, Camerino et al., 2008; Lian et al., 2015; Labbafinejad et al., 2014; Mazloumi et al., 2012; Vedovato \& Monteiro, 2014; Walker et al., 2015). Specifically, duration and quality of sleep are generally related to higher levels of WA, whereas lack of sleep is related to lower levels of WA. In sum, 
lifestyle variables are significantly related to WA even when accounting for other variables, and therefore, should be considered in any comprehensive investigation of WA.

Personality and other personal characteristics. As noted, one line of research that is beginning to receive research attention is the examination of personality and WA. Although this research is still is very limited, the results seem promising. For example, McGonagle and colleagues (2015) found that conscientiousness, emotional stability, and positive affectivity were positively related to perceived WA. In addition to personality, other personal characteristics have been investigated as antecedents to WA. For example, Chung and colleagues (2015) found a positive relationship between cognitive ability and WA in workers over the age of 55 that worked in heavy industry (Chung et al., 2015). Koolhaas and colleagues (2014) found a positive relationship between active problem-focused coping and WA and also found a negative relationship between avoidant coping and WA in a large sample of workers aged 45 or older representing multiple sectors in the Netherlands. Interestingly, research has found that general self-efficacy was similarly related to both perceived WA and the WAI whereas the relationship between perceived WA and job self-efficacy appeared to be stronger than the relationship between the WAI and job self-efficacy (McGonagle et al., 2015). Overall, there is a positive relationship between the personal characteristics and WA when measured as perceived WA or the combined perceived and objective WA (i.e., the WAI). Future research should investigate whether a stronger relationship may exist with perceived WA given that it could be more susceptible to influence from one's personal characteristics.

Researchers have also begun to examine the relationship between different subjective age and WA (e.g., Barnes-Farrell, Rumery, \& Swody, 2002; Bobko \& Barishpolets, 2002; Freude, Jakob, Martus, Rose, \& Seibt, 2010; Peters et al., 2016). Age conceptualizations beyond 
chronological age capture different ways individuals experience the aging process (Kooij, De Lange, Jansen, \& Dikkers, 2008) and can be operationalized in a variety of ways such as subjective/psychological age (i.e., felt age, look age, ideal age), organizational age (i.e., tenure), lifespan age (i.e., family status like number of dependents and perceptions of one's life stage) and functional age (i.e., perceived health status and the presence of a chronic health condition. among others). Peters and colleagues (2016) found support for organization age, lifespan age, and functional age having small to medium effects on WA in a sample of nurses. Bobko and Barishpolets (2002) found a significant relationship between felt age discrepancy and WA, and Koolhaas and colleagues (2011) found a significant relationship between functional age and work ability. The promising results examining different conceptualizations of age and WA warrants further research. In sum, although the personality and personal characteristics research is still in its beginning stages of exploration with WA, the initial evidence points to this as a fruitful future area for research.

Attitudes. Individual attitudes are another area of examination receiving increasing attention in recent WA research. Some of the attitudinal research has found a positive relationship between broader attitudes like quality of life satisfaction and WA (e.g., Arandjelovic, Nikolic, \& Stamenkovic, 2010; Milosevic et al., 2011). Research investigating work-specific attitudes and WA such as engagement (Airila et al., 2012; Mache et al., 2013, Rongen, Robroek, Schaufeli, \& Burdorf, 2014) and job satisfaction (Palermo et al., 2013; Tuomi et al., 2001; Martinez \& Latorre, 2006) supports the notion that high engagement and job satisfaction are related to greater levels of WA. However, the direction of this relationship has not been fully explored. For instance, being more engaged with one's job could result in greater 
perceptions of WA, but those who have greater perceptions of WA could also be more willing to allocate more effort and be more engaged at work.

\section{Outcomes of WA}

As we observed in the previous section, there is a substantial literature examining WA as an outcome, and the focus has been on factors (e.g., injuries; stressors) that might impact a person's WA. This may be largely due to the initial purpose of WA, to identify links between WA and disability status and retirement, which identified WA as a key mechanism for extending working careers, thereby necessitating research identifying its antecedents in order to develop WA promoting interventions. Theoretically, people's level of WA could influence their ability to enact adaptive behaviors such as selection, optimization, and compensation that could help prevent negative outcomes and increase the likelihood of successful adaptation resulting in positive outcomes. However, there is also a relatively smaller body of research where WA is situated as a predictor of a variety of outcomes ranging from long-term sickness and disability claims to life and retirement satisfaction. In this section, we treat WA as a predictor of the outcomes to simplify our discussion. However, in our conceptual figure (Figure 1) we acknowledge that there may be more complex bi-directional relationship between WA and these outcome variables. In other words, some of these outcome variables could also influence one's WA. For instance, we generally examine WA as a predictor of retirement, but when someone retires, we could see how that could dramatically the retiree's assessment of their WA. Another example, one's WA could influence their task performance, but if one's task performance evaluation could also influence one's assessment of their WA.

WA and sickness-related outcomes. The extant literature supports a consistent negative relationship between WA and sickness-related absences and sick leave (e.g., Bertilsson, Vaez, 
Waern, Ahlborg Jr., \& Hensing, 2015; Habibi et al., 2012; Reeuwijk et al., 2015; Tuomi et el., 2001) including long-term absence (e.g., Kujala et al., 2006; Notenbomer, Groothoff, van Rhenen, \& Roelen, 2015; Schouten et al., 2015). The significant negative relationship is not surprising given the fact that one of the items of the WAI asks about the number of sickness related absences in the previous 12 months. Considering that there is a conceptual overlap with sickness as an outcome, we expect that there would be a stronger relationship between objective WA and the sickness-related outcomes compared to perceived WA because objective WA reflects diagnosed health issues. This also highlights our concerns regarding the operationalization of WA, and how some WA measures may be confounding predictors of WA into the WA measure itself.

WA and disability-related outcomes. WA is negatively related to risk of future disability/disability pension status (Alavinia, De Boer, Van Duivenbooden, Frings-Dresen, \& Burdorf, 2009; Ilmarinen \& Tuomi, 1992; Roelen et al., 2014). In other words, lower WA increases the likelihood of disability and utilization of disability services, which can impact both organizations and society through straining economic growth due to additional resources having to be allocated to these programs. Similar to the sickness-related outcomes, we expect that there would be a stronger relationship between objective WA and the disability-related outcomes compared to perceived WA because objective WA reflects diagnosed health issues. That said, low levels of perceived WA may also be a factor that moves people to consider and actually apply for disability or long term sick leave.

WA and withdrawal. WA has also been related to withdrawal behaviors including organizational and professional turnover (Camerino et al., 2006; Rongen et al., 2014) and early retirement and early retirement intentions (Heponiemi et al., 2008; Pit \& Hansen, 2014; von 
Bonsdorff et al., 2009; von Bonsdorff et at., 2011). The studies used a mixture of perceived WA and the WAI which emphasize the importance of maintaining WA no matter how you operationalize it in order to retain workers in organizations, professions, and the workforce more broadly. In a longitudinal study, von Bonsdorff and colleagues found a negative relationship between WA and mortality (von Bonsdorff et al., 2011), which indicates that WA is not only important in predicting one's work-span but can also influence one's lifespan. This is likely due to the fact that employment is tied to many important benefits - not only financial security, but also other benefits such as health insurance and social connectedness.

WA and positive work-related outcomes. Although initial research focused on WA as an antecedent of negative work and health outcomes, WA has also been found to be an antecedent of several positive work-related outcomes. Van den Berg and colleagues (2011) found that productivity loss was lower for individuals with excellent WA. Additionally, Tuomi and colleagues found that WA predicted an individual's quality of work (Tuomi et al., 2001) and their job satisfaction (Tuomi et al., 2001). Although objective WA may reflect the capacity to perform well, one's perceived WA likely plays a critical role in determining the effect of one's WA on these job outcomes. That is, even if someone has low levels of objective WA, if there is a high level of perceived WA, they may still be quite satisfied in their role and perform at a high level. Although we present WA as an antecedent to these positive job outcomes, we acknowledge that there may be reciprocal relationships among WA and these job outcomes, and we encourage further and more rigorous tests to clarify the causal nature of these relationships.

WA and outcomes outside the workplace. Research has also examined outcomes outside of the work context and found positive relationships between WA and several broader outcomes. For example, Sorensen and colleagues (2008) found that WA had a positive 
relationship with perceived quality of life. Relatedly, WA predicting life satisfaction has also been supported (Tuomi et al., 2001). In addition, WA has also been tied to higher levels of subjective well-being (Sjögren-Rönkä et al., 2002). Finally, WA has been tied to positive retirement experiences. In fact, Feldt and colleagues found that those with higher WA had greater levels of personal goal pursuit in retirement and Tuomi and colleagues (1991) found a similar positive relationship between WA and self-reported successful and meaningful retirement.

In summary, the research supports WA as a significant predictor of important short-term and long-term outcomes for individuals, organizations, and society. Of interest and something that we would like to note is the positioning of WA as both a predictor and outcome of several variables (e.g., depression, mental health, job satisfaction, life satisfaction). In other words, a fruitful line of research would be to examine the dynamic and likely reciprocal relationships that seem to exist between these variables and WA.

\section{Workplace Interventions to Support WA}

Given that WA was originally developed to establish expectations regarding how long individuals could be expected to continue working, and how to maintain the capacity to work among employees, researchers have developed interventions designed to increase or maintain WA, and many have found positive results. Truxillo and colleagues (2015) suggest a health promotion/prevention framework to address workplace aging, and this framework can also be useful in discussing interventions aimed at preventing the decline of WA or promoting WA after declines have taken place. We frame our discussion of WA within the health promotion/prevention framework, and distinguish between interventions focusing on the individual, group, and organizational level. We note that there is a useful distinction between 
interventions focused on improving or maintaining perceived versus objective WA. In other words, a human factors work redesign program may be more focused on changing actual WA, whereas a program focused on psychological enrichment of a job may be more focused on changing perceived WA. Although our review focuses on employed samples where WA was used as an intervention outcome, it is important to note that there is also a wealth of WA literature on return to work interventions for those with chronic illnesses and other serious illnesses or injuries that have forced them out of the workforce.

Individual-focused interventions. A number of WA interventions are concentrated at the level of the individual. Programs focused on increasing an individual's physical activity outside of work have shown success in improving WA. For instance, Flannery and colleagues (2012), in a quasi-experimental test of the Worksite Heart Health Improvement Project (WHHIP), observed significant improvement on the WAI for the intervention group who participated a physical activity and healthy eating (i.e., reduction in salt and fat intake) program. In addition, Von Theile Schwarz and colleagues (2008) observed that participants in two separate intervention conditions (mandatory 2.5 hours of exercise during work hours or a reduction in hours from 40 to 37.5) maintained their perceived WA compared to the reference group, which observed a loss of perceived WA over the 12-month program. From a theoretical perspective, these findings align well with the JD-R. Specifically, personal resource gains via increased physical ability and increased time to recover or engage in health promoting activities, have a positive influence on WA, which is identified in the health promotion pathway of the JD-R.

Stress management training has also been studied as a way to increase WA through increasing an individual's ability to effectively cope with stressors. For example, Wu and colleagues (2006) found a significant improvement on the WAI over a 12-month period among 
teachers in China who participated in a stress management training intervention compared to a control group. McGonagle and colleagues (2014) found that a 12-week phone-based coaching intervention to manage challenges related to illness and reduce strain resulted in increased perceived WA compared to the waitlisted control group. Additionally, in a unique stressreduction intervention Sahlin and colleagues (2014) observed a significant increase in perceived WA and reduced self-reported sickness absence (WAI item 5) following a 12-week nature-based stress management course. Taken together, the reduced strain related to these interventions could reflect an increase in personal resources that could be applied to implementing adaptive behaviors like selection, optimization, and compensation that has led to either improving or maintaining WA.

\section{Group- and Organization-Focused WA Interventions}

In addition to individual-focused interventions, at least one study incorporated a groupbased intervention and demonstrated a significant improvement in WA. Vouri and colleagues (2012) found in a randomized controlled field experiment that a group-based training intervention focused on building employee preparedness for career management had a significant positive influence on the mental resources facet of the WAI. Additional research examining group-based interventions is needed, but the work of Vouri and colleagues is a promising start to this type of intervention.

A final category of interventions is organization-focused interventions. Marqueze and colleagues (2008) found that an administrative restructuring focused on reducing the sources of dissatisfaction among teachers resulted in an increase on the WAI over the two-year study period. Moreover, von Thielen et al. (2008) included an organization-focused type intervention in the sense that they reduced the work hours for full time employees and saw improvement in 
perceived WA. In addition, Ahlstrom and colleagues (2013) found that creating supportive work conditions (i.e., ability to influence work, access to development, degree of freedom at work, work meaningfulness, leadership quality, social support, sense of community and work satisfaction) resulted in increased WA when measured with the WAI over the 12-month period, and these effects were found as a stand-alone intervention, as well as when combined with a workplace rehabilitation program. These findings are in direct alignment with the wealth of research from previous research using the JD-R to establish the positive influence of supportive work conditions on positive health and job outcomes.

The interventions summarized in this section are encouraging with regard to identifying effective strategies and programs for maintaining and improving perceived WA as well as scores on the WAI. It is also notable that these effective strategies target multiple levels (i.e., individual, group, and organization), which shows that a comprehensive intervention addressing multiple levels has potential for being successful. Although these findings show that interventions can be effective in supporting WA, more intervention research is needed, particularly for group and organization-level interventions. Further, future research should consider country-level interventions such as the implementation of policies allowing for life-long learning accounts where individuals and organizations contribute, and could help the workforce maintain and improve WA throughout the lifespan. As with other workplace intervention research, we should also be asking "when?" and "for whom?" does an intervention work to increase WA, that is, examining moderators of intervention effectiveness. Finally, we encourage future interventions to draw more heavily on theoretical models, such as the JD-R and lifespan development theories to identify additional changes that organizations can make to promote WA. To aid future 
intervention research we have created Table 2, which summarizes the interventions we covered and provides some theoretically-based explanations as to why the interventions were successful.

\section{Future Research}

Although we have noted research needs throughout this review, we see several broad overarching areas that are ripe for future research. We organize our research recommendations into three categories - WA concept clarification, lifespan development and theoretical integration, and multi-level approach to WA — and provide a detailed discussion of them below. We provide a summary of our future research recommendations in Table 3.

\section{WA Concept Clarification}

This review has illustrated that the greatest research gap in the WA literature is that the WA construct needs to be fixed within a nomological network of other variables, and its antecedents and outcomes need to be clearly established. Perceived WA is often articulated as how well a person believes their physical and psychological abilities match those required by their job. For this reason, we see it as important to differentiate the WA construct from measures of person-job (PJ) fit, particularly measures of subjective fit, which has its own established literature (e.g., Kristoff-Brown, Zimmerman, \& Johnson, 2005). This is particularly relevant given recent arguments about the importance of perceived fit approaches to understanding the individual's response to aging at work (Perry, Dokko, \& Golom, 2012). McGonagle and colleagues (2015) provide an example of where advancements in building the WA nomological network should go. Importantly, they assessed a wide range of antecedents and outcomes of perceived WA, distinguished between perceived WA and objective health-related measures of WA, and demonstrated discriminant validity between perceived WA and some similar constructs (e.g., job self-efficacy). Therefore, future research should examine whether the way WA is 
measured (i.e., perceived and objective health-related) and how P-J fit is measured (i.e., perceived and objective) affects their interrelationship and relationship with other measures, and continue to empirically investigate the discriminant and incremental validity of these two constructs. This type of research should help position WA in the literature and test the boundaries of WA.

At the same time, such research on the nomological network of WA is impossible without acknowledging the wide variety of WA measures, such as objective health-related WA and perceived WA. Further research should extend these types of investigations to explore conceptual distinctions and interrelationships among the perceived and more objective healthrelated operationalization of WA, but also explore domain-specific aspects of WA such as physical, mental/cognitive, psychological, and social and their potential differential relationships across job contexts and across work and life outcomes. Specifically, this not only includes examining relationship with other constructs and their usefulness in predicting outcomes such as disability and retirement, but also looking at these domain-specific WA determinants and their relationships with different outcomes across and within job contexts. In other words, what is the impact of the different adaptations of the measurement of WA on its nomological network? Therefore, we call for future research to assess the relative value of the different WA measures for predicting different constructs. Identifying the most efficacious measures will hopefully lead to more consistency in the measurement and conceptualization of WA, increase the comparability of results, and thus advance our collective knowledge of WA's nomological network. Relatedly, we would also like to reemphasize our recommendation to discontinue the use of single-item WA measures unless there is theoretical advancement as to how a single-item encompasses the complex and seemingly, multi-dimensional WA construct. Additionally, 
qualitative research on WA, particularly perceived WA, is in order. For example, a study examining what individuals are thinking (i.e., think aloud analysis; e.g., Fonteyn, Kuipers, \& Grobe, 1993) when answering questions about WA could help provide deeper insight into the perceptions of respondents regarding WA and likewise its measurement. Finally, we also noted in this paper that WA has been treated as both an outcome and antecedent in relation to other variables (e.g., depression, mental health, job satisfaction, life satisfaction). To help clarify the temporal relationship among WA and these constructs, we recommend future research to implement cross-lagged research designs in order to investigate the potential dynamic and reciprocal relationships that seem to exist between these variables and WA.

\section{Lifespan Development and Theoretical Integration}

We also call for further theoretical integration of WA into the aging literature and we have provided a conceptual model to guide future lifespan development integration with WA (see Figure 1). For example, given the relationship between age and WA, the mechanisms that influence WA from a lifespan development perspective are emerging. For example, the few studies examining the influence of SOC (Baltes \& Baltes, 1990) behaviors on WA have found that WA is often positively related to these behaviors (e.g., Müller et al., 2012; Müller et al., 2013; Müller, Heiden, Herbig, Poppe, \& Angerer, 2016; Riedel et al., 2015; von Bonsdorff et al., 2014). Although this research is promising, additional research that helps improve the generalizability of these findings across cultures and occupations is greatly needed.

However, SST has been less firmly integrated into the WA literature (Carstensen et al., 1999). SST proposes that as we age our future time perspective decreases, which leads to increases the social/relational motivations. We view these factors as potentially having a strong influence on WA, and believe this may be a fruitful line of additional research. That is, to better 
integrate SST in the WA literature, research can work to answer questions regarding how one's future time perspective influences WA, and how social/relational motivations may serve as a mechanism between future time perspective and WA. For instance, one's assessment of their WA could be fixed within how constrained or expansive their future time perspective is. In other words, a person may evaluate their level of WA as higher or lower depending on how much longer they want to be in the workforce based on their future time horizons. Moreover, shifts toward more social and relational motivations may influence one's evaluation of their WA if they are in a job that provides opportunities to act on those motives. Specifically, jobs that encourage mentorship and similar social and relational behaviors may be particularly beneficial for older workers. Ultimately, we believe this research should be conducted in conjunction with the WA research drawing on the JD-R to determine the effectiveness of improving employees' work environment across the lifespan.

\section{Multi-Level Approach to WA}

We see future research examining WA from a multi-level perspective as another fruitful line of future research. Although a few studies have examined the impact of organizational culture and climate (e.g., Feldt et al., 2009; Larsson et al., 2012; Palermo et al., 2013) on WA, this research was at the level of individual perception of culture and climate and not at the aggregate level. Therefore, future research should examine aggregate levels of WA at a team, department, or even organizational level that could be an indication of the existence of a work ability climate, which would be a shared perception of WA that could be influenced by policies, procedures, practices, and leadership. A WA climate could serve as an indicator of the effectiveness of organizational-level interventions focused on improving WA. Research by Boehm and colleagues (2014) and Kunze and colleagues (2011) examines age-related concepts 
at the group and organizational levels of analysis and can serve as a guide for this type of research (Boehm, Kunze, \& Bruch, 2014; Kunze, Boehm, \& Bruch, 2011). Moreover, recent research by Von Bonsdorff and colleagues (2016) provides a specific example of how researchers aggregated WA at the company level when they investigated WA as a mediator between company age and company performance.

WA could also be influenced at a societal level from the perspective of societal, professional, and industry-specific norms in the form of expectations and stereotypes that become internalized and influence our perceptions of what our WA "should be." For instance, certain cultures could have a tendency to devalue older workers. Moreover, there may be certain jobs and occupations where age (i.e., in the form of experience and wisdom) may be valued, and other jobs and occupations where age is devalued. We expect that WA would be significantly impacted by both job- and occupation-related norms as well as different levels of job resources and demands across jobs and occupations. In other words, there could be an optimal level of certain job demands and resources in specific jobs and occupations that could be useful to maintain and promote WA. For example, sedentary jobs are not good for one's health, resulting a negative impact on WA, but too much physical activity, or high physical demands, in one's role also negatively influence WA. Moreover, jobs and occupations with a certain level of cognitive demands could develop and maintain an individual's WA because it keeps their cognitive capabilities sharp, but extremely high levels of cognitive demands could be detrimental to one's WA because age-related declines in fluid intelligence capacity over the lifespan. Therefore, conducting studies that assess group, and organization-level beliefs (both implicit and explicit) about the relative value of age, in combination with job resources and demands, and how these contribute to WA would help us understand potential systematic barriers to improving WA. 
Further, identifying group level WA and group level factors that influence WA could be extremely helpful in identifying which interventions techniques organizations should pursue in order to best match intervention strategies with the needs of the workforce.

\section{Conclusion}

In this review, we have synthesized the extant, multidisciplinary research literature on WA in order to provide a more comprehensive understanding of the construct and guide future studies. We have discussed a handful of potential lines of research that will help further extend, test the boundaries, and facilitate the integration of the WA concept into the aging and workplace literature. We see a bright future for the burgeoning WA literature. We invite future research to explore these avenues so that we can fully investigate the promising concept of WA in light of the aging workforce and relatively few answers we have to manage this important demographic trend. 


\section{WORK ABILITY REVIEW}

\section{References}

Abma, F. I., van der Klink, J. J., \& Bültmann, U. (2013). The work role functioning questionnaire 2.0 (Dutch version): examination of its reliability, validity and responsiveness in the general working population. Journal of occupational rehabilitation, $23,135-147$.

Ahlstrom, L., Grimby-Ekman, A., Hagberg, M., \& Dellve, L. (2010). The work ability index and single-item question: Associations with sick leave, symptoms, and health-a prospective study of women on long-term sick leave. Scandinavian Journal of Work, Environment \& Health, 36, 404-412.

Ahlstrom, L., Hagberg, M., \& Dellve, L. (2013). Workplace rehabilitation and supportive conditions at work: a prospective study. Journal of Occupational Rehabilitation, 23, 248260.

Airila, A., Hakanen, J., Punakallio, A., Lusa, S., \& Luukkonen, R. (2012). Is work engagement related to work ability beyond working conditions and lifestyle factors?. International Archives of Occupational and Environmental Health, 85, 915-925.

Airila, A., Hakanen, J., Schaufeli, W. B., Luukkonen, R., Punakallio, A., \& Lusa, S. (2014). Are job and personal resources associated with work ability 10 years later? Work \& Stress, $28,87-105$.

Alavinia, S. M., De Boer, A. G. E. M., Van Duivenbooden, J. C., Frings-Dresen, M. H. W., \& Burdorf, A. (2009). Determinants of work ability and its predictive value for disability. Occupational Medicine, 59, 32-37. Doi: 10.1093/occmed/kqn148. 


\section{WORK ABILITY REVIEW}

Arandjelovic, M., Nikolic, M., \& Stamenkovic, S. (2010). Relationship between burnout, quality of life, and work ability index — directions in prevention. The Scientific World Journal, 10, 766-777.

Arvidson, E., Börjesson, M., Ahlborg, G., Lindegård, A., \& Jonsdottir, I. H. (2013). The level of leisure time physical activity is associated with work ability-a cross sectional and prospective study of health care workers. BioMed Central Public Health, 13, 855-861.

Bakker, A. B., \& Demerouti, E. (2007). The job demands-resources model: State of the art. Journal of Managerial Psychology, 22, 309-328.

Baltes, P. B. (1997). On the incomplete architecture of human ontogeny: Selection, optimization, and compensation as foundation of developmental theory. American Psychologist, 52, 366-380.

Baltes, P. B., \& Baltes, M. M. (1990). Psychological perspectives on successful aging: The model of selective optimization with compensation. In P. B. Baltes \& M. M. Baltes (Eds.), Successful aging: Perspectives from the behavioral sciences (pp. 1-34). New York: Cambridge University Press.

Barnes-Farrell, J. L., Rumery, S. M., \& Swody, C. A. (2002). How do concepts of age relate to work and off-the-job stresses and strains? A field study of health care workers in five nations. Experimental Aging Research, 28, 87-98.

Bethge, M., \& Radoschewski, F. M. (2010). Physical and psychosocial work stressors, healthrelated control beliefs and work ability: cross-sectional findings from the German Sociomedical Panel of Employees. International Archives of Occupational and Environmental Health, 83, 241-250. 


\section{WORK ABILITY REVIEW}

Bethge, M., Radoschewski, F. M., \& Gutenbrunner, C. (2012). Effort-reward imbalance and work ability: cross-sectional and longitudinal findings from the Second German Sociomedical Panel of Employees. BioMed Central Public Health, 12, 1-9.

Bertilsson, M., Vaez, M., Waern, M., Ahlborg Jr, G., \& Hensing, G. (2014). A prospective study on self-assessed mental well-being and work capacity as determinants of all-cause sickness absence. Journal of Occupational Rehabilitation, 25, 52-64.

Bobko, N. A., \& Barishpolets, A. T. (2002). Work ability, age and its perception, and other related concerns of Ukraine health care workers. Experimental aging research, 28, 59-71.

Boehm, S. A., Kunze, F., \& Bruch, H. (2014). Spotlight on age-diversity climate: The impact of age-inclusive HR practices on firm-level outcomes. Personnel Psychology, 67, 667-704.

Boschman, J. S., Van der Molen, H. F., Frings-Dresen, M. H. W., \& Sluiter, J. K. (2014). The impact of common mental disorders on work ability in mentally and physically demanding construction work. International Archives of Occupational and Environmental Health, 87, 51-59.

Camerino, D., Conway, P. M., Van der Heijden, B. I. J., Estryn-Behar, M., Consonni, D., Gould, D., \& Hasselhorn, H. M. (2006). Low-perceived work ability, ageing and intention to leave nursing: a comparison among 10 European countries. Journal of Advanced Nursing, 56, 542-552.

Camerino, D., Conway, P. M., Sartori, S., Campanini, P., Estryn., Béhar, M., van der Heijden, B. I. J. M., \& Costa, G. (2008). Factors affecting work ability in day and shift working nurses. Chronobiology International, 25, 425-442.

Carstensen, L. L., Isaacowitz, D. M., \& Charles, S. T. (1999). Taking time seriously: A theory of socioemotional selectivity. American Psychologist, 54, 165-181. 


\section{WORK ABILITY REVIEW}

Charles, S. T. (2010). Strength and vulnerability integration: a model of emotional well-being across adulthood. Psychological Bulletin, 136, 1068-1091.

Chiu, M. C., Wang, M. J. J., Lu, C. W., Pan, S. M., Kumashiro, M., \& Ilmarinen, J. (2007). Evaluating work ability and quality of life for clinical nurses in Taiwan. Nursing Outlook, $55,318-326$.

Chung, J., Park, J., Cho, M., Park, Y., Kim, D., Yang, D., \& Yang, Y. (2015). A study on the relationships between age, work experience, cognition, and work ability in older employees working in heavy industry. Journal of Physical Therapy Science, 27, 155-157.

Costa, G., \& Sartori, S. (2007). Ageing, working hours and work ability. Ergonomics, 50, 19141930.

Demerouti, E., Bakker, A. B., Nachreiner, F., \& Schaufeli, W. B. (2001). The job demandsresources model of burnout. Journal of Applied Psychology, 86, 499-512.

de Souza Magnago, T. S. B., de Lima, A. C. S., Prochnow, A., da Silva Ceron, M. D., Tavares, J. P., \& de Souza Urbanetto, J. (2012). Intensity of musculoskeletal pain and (in) ability to work in nursing. Rev. Latino-Am. Enfermagem, 20, 1125-33.

De Zwart, B. C. H., Frings-Dresen, M. H. W., \& Van Duivenbooden, J. C. (2002). Test-retest reliability of the Work Ability Index questionnaire. Occupational Medicine, 52, 177-181.

El Fassi, M., Bocquet, V., Majery, N., Lair, M. L., Couffignal, S., \& Mairiaux, P. (2013). Work ability assessment in a worker population: comparison and determinants of Work Ability Index and work ability score. BMC Public Health, 13, 305-315.

Ellis, A. M., Bauer, T. N., Mansfield, L. R., Erdogan, B., Truxillo, D. M., \& Simon, L. S. (2015). Navigating uncharted waters: Newcomer socialization through the lens of stress theory. Journal of Management, 41, 203-235. 


\section{WORK ABILITY REVIEW}

Elo, A. L., Ervasti, J., Kuosma, E., \& Mattila, P. (2008). Evaluation of an organizational stress management program in a municipal public works organization. Journal of Occupational Health Psychology, 13, 10-23.

Elovainio, M., Kuusio, H., Aalto, A. M., Sinervo, T., \& Heponiemi, T. (2010). Insecurity and shiftwork as characteristics of negative work environment: psychosocial and behavioural mediators. Journal of Advanced Nursing, 66, 1080-1091.

Eskelinen, L., Kohvakka, A., Merisalo, T., Hurri, H., \& Wägar, G. (1991). Relationship between the self-assessment and clinical assessment of health status and work ability. Scandinavian Journal of Work, Environment \& Health, 17, 40-47.

Feldt, T., Hyvönen, K., Mäkikangas, A., Kinnunen, U., \& Kokko, K. (2009). Development trajectories of Finnish managers' work ability over a 10-year follow-up period. Scandinavian Journal of Work, Environment \& Health, 35, 37-47.

Fischer, F. M., Borges, F. D. S., Rotenberg, L., Latorre, M. R. D. O., Soares, N. S., Rosa, P. F. L. S., \& Landsbergis, P. (2006). Work ability of health care shift workers: what matters?. Chronobiology International, 23, 1165-1179.

Fischer, F. M., \& Martinez, M. C. (2011). Work ability among hospital food service professionals: multiple associated variables require comprehensive intervention. Work, $41,3746-3752$.

Fischer, F. M., \& Martinez, M. C. (2013). Individual features, working conditions and work injuries are associated with work ability among nursing professionals. Work, 45, 509-517.

Flannery, K., Resnick, B., \& McMullen, T. L. (2012). The impact of the Worksite Heart Health Improvement Project on work ability: A pilot study. Journal of Occupational and Environmental Medicine, 54, 1406-1412. 


\section{WORK ABILITY REVIEW}

Fonteyn, M. E., Kuipers, B., \& Grobe, S. J. (1993). A description of think aloud method and protocol analysis. Qualitative Health Research, 3, 430-441.

Freude, G., Jakob, O., Martus, P., Rose, U., \& Seibt, R. (2010). Predictors of the discrepancy between calendar and biological age. Occupational Medicine, 60, 21-28.

Fuß, I., Nübling, M., Hasselhorn, H. M., Schwappach, D., \& Rieger, M. A. (2008). Working conditions and Work-Family Conflict in German hospital physicians: psychosocial and organisational predictors and consequences. BioMed Central Public Health, 8, 353-70.

Galatsch, M., Li, J., Derycke, H., Müller, B. H., \& Hasselhorn, H. M. (2013). Effects of requested, forced and denied shift schedule change on work ability and health of nurses in Europe-Results from the European NEXT-Study. BioMed Central Public Health, 13, 1137-1147.

Ghaddar, A., Ronda, E., \& Nolasco, A. (2011). Work ability, psychosocial hazards and work experience in prison environments. Occupational Medicine, 61, 503-508.

Glise, K., Hadzibajramovic, E., Jonsdottir, I. H., \& Ahlborg, G. (2010). Self-reported exhaustion: a possible indicator of reduced work ability and increased risk of sickness absence among human service workers. International Archives of Occupational and Environmental Health, 83, 511-520.

Golubic, R., Milosevic, M., Knezevic, B., \& Mustajbegovic, J. (2009). Work related stress, education and work ability among hospital nurses. Journal of Advanced Nursing, 65, 2056-2066.

Gould, R., Ilmarinen, J., Järvisalo, J., \& Koskinen, S. (2008) Dimensions of work ability: Results of the Health 2000 Survey. Vaasa, Helsink: Waasa Graphics Oy. 


\section{WORK ABILITY REVIEW}

Guidi, S., Bagnara, S., \& Fichera, G. P. (2012). The HSE indicator tool, psychological distress and work ability. Occupational Medicine, 62, 203-209

Habibi, E., Dehghan, H., Zeinodini, M., Yousefi, H., \& Hasanzadeh, A. (2012). A study on work ability index and physical work capacity on the base of fax equation VO2 max in male nursing hospital staff in Isfahan, Iran. International Journal of Preventive Medicine, 3, 776-782.

Hakanen, J. J., Bakker, A. B., \& Schaufeli, W. B. (2006). Burnout and work engagement among teachers. Journal of School Psychology, 43, 495-513.

Han, L., Shi, L., Lu, L., \& Ling, L. (2014). Work ability of Chinese migrant workers: the influence of migration characteristics. BioMed Central Public Health, 14, 1-8.

Hinkin, T. R. (1998). A brief tutorial on the development of measures for use in survey questionnaires. Organizational Research Methods, 1, 104-121.

Heponiemi, T., Kouvonen, A., Vänskä, J., Halila, H., Sinervo, T., Kivimäki, M., \& Elovainio, M. (2008). Health, psychosocial factors and retirement intentions among Finnish physicians. Occupational Medicine, 58, 406-412.

Ilmarinen, J. (2009). Work ability—a comprehensive concept for occupational health research and prevention. Scandinavian Journal of Work, Environment \& Health, 35, 1-5.

Ilmarinen, J., Tuomi, K., Eskelinen, L., Nygård, C. H., Huuhtanen, P., \& Klockars, M. (1991a). Background and objectives of the Finnish research project on aging workers in municipal occupations. Scandinavian Journal of Work, Environment \& Health, 17, 7-11.

Ilmarinen, J., Tuomi, K., Eskelinen, L., Nygård, C. H., Huuhtanen, P., \& Klockars, M. (1991b). Summary and recommendations of a project involving cross-sectional and follow-up 


\section{WORK ABILITY REVIEW}

studies on the aging worker in Finnish municipal occupations (1981-1985).

Scandinavian Journal of Work, Environment \& Health, 17, 135-141.

Ilmarinen, J., Tuomi, K., \& Klockars, M. (1997). Changes in the work ability of active employees over an 11-year period. Scandinavian Journal of Work, Environment \& Health, 23, 49-57.

Ilmarinen, V., Ilmarinen, J., Huuhtanen, P., Louhevaara, V., \& Näsman, O. (2015). Examining the factorial structure, measurement invariance and convergent and discriminant validity of a novel self-report measure of work ability: work ability-personal radar. Ergonomics, $58,1445-1460$.

Ilmarinen, J., Tuomi, K., \& Seitsamo, J. (2005). New dimensions of work ability. In International Congress Series, 1280, 3-7.

Ilmarinen, J., \& Tuomi, K. (1992). Work ability of aging workers. Scandinavian Journal of Work, Environment \& Health, 18, 8-10.

Järvikoski A, Härkäpää K, Mannila S (2001) Moniulotteinen työkykykäsitys ja työkykyä ylläpitävä toiminta [Multidimensional work ability concept and maintenance of work ability]. Kuntoutus [Finnish Journal of Rehabilitation], 24, 3-11.

Ję dryka-Góral, A., Bugajska, J., Łastowiecka, E., Najmiec, A., Rell-Bakalarska, M., Bownik, I., \& Kochmański, M. (2006). Work ability in ageing workers suffering from chronic diseases. International Journal of Occupational Safety and Ergonomics, 12, 17-30.

Kaewboonchoo, O., Saleekul, S., \& Usathaporn, S. (2011). Factors related to work ability among Thai workers. Southeast Asian Journal of Tropical Medicine and Public Health, 42, 225230. 


\section{WORK ABILITY REVIEW}

Kaleta, D., Makowiec-Dąbrowska, T., \& Jegier, A. (2006). Lifestyle index and work ability. International Journal of Occupational Medicine and Environmental Health, 19, $170-177$.

Kampfe, C. M., Wadsworth, J. S., Mamboleo, G. I., \& Schonbrun, S. L. (2008). Aging, disability, and employment. Work: A Journal of Prevention, Assessment and Rehabilitation, 31, 337-344.

Kanfer, R., \& Ackerman, P. L. (2004). Aging, Adult Development, and Work Motivation. Academy of Management Review, 29, 440-458.

Karasek, R.A. (1979). Job demands, job decision latitude, and mental strain: Implications for job redesign. Administrative Science Quarterly, 24, 285-308. doi:10.2307/2392498.

Karttunen, J. P., \& Rautiainen, R. H. (2011). Risk factors and prevalence of declined work ability among dairy farmers. Journal of Agricultural Safety and Health, 17, 243-257.

Kooij, D., De Lange, A., Jansen, P., \& Dikkers, J. (2008). Older workers' motivation to continue to work: Five meanings of age: A conceptual review. Journal of Managerial Psychology, 23, 364-394.

Koolhaas, W., van der Klink, J. J., Groothoff, J. W., \& Brouwer, S. (2011). Towards a sustainable healthy working life: associations between chronological age, functional age and work outcomes. The European Journal of Public Health, 22, 424-429.

Koolhaas, W., van der Klink, J. J., de Boer, M. R., Groothoff, J. W., \& Brouwer, S. (2014). Chronic health conditions and work ability in the ageing workforce: the impact of work conditions, psychosocial factors and perceived health. International Archives of Occupational and Environmental Health, 87, 433-443. 


\section{WORK ABILITY REVIEW}

Kristof-Brown, A. L., Zimmerman, R. D., \& Johnson, E. C. (2005). Consequences of individuals' misfit at work: A meta-analysis of person-job, person-organization, persongroup, and person-supervisor fit. Personnel psychology, 58, 281-342.

Kujala, V., Remes, J., Ek, E., Tammelin, T., \& Laitinen, J. (2005). Classification of work ability index among young employees. Occupational Medicine, 55, 399-401.

Kujala, V., Tammelin, T., Remes, J., Vammavaara, E., Ek, E., \& Laitinen, J. (2006). Work ability index of young employees and their sickness absence during the following year. Scandinavian Journal of Work, Environment \& Health, 32, 75-84.

Kunze, F., Boehm, S. A., \& Bruch, H. (2011). Age diversity, age discrimination climate and performance consequences - a cross organizational study. Journal of Organizational Behavior, 32, 264-290.

Labbafinejad, Y., Ghaffari, M., Bahadori, B., Mohammadi, S., Abdi, A., Namvar, M., \& Attarchi, M. (2014). The effect of sleep disorder on the work ability of workers in a car accessories manufacturing plant. Medical journal of the Islamic Republic of Iran, 28, 111-119.

Laitinen, J., Näyhä, S., \& Kujala, V. (2005). Body mass index and weight change from adolescence into adulthood, waist-to-hip ratio and perceived work ability among young adults. International Journal of Obesity, 29, 697-702.

Larsson, A., Karlqvist, L., Westerberg, M., \& Gard, G. (2012). Identifying work ability promoting factors for home care aides and assistant nurses. BMC Musculoskeletal Disorders, 13, 1-11. 


\section{WORK ABILITY REVIEW}

Lederer, V., Loisel, P., Rivard, M., \& Champagne, F. (2014). Exploring the diversity of conceptualizations of work (dis) ability: a scoping review of published definitions. Journal of Occupational Rehabilitation, 24, 242-267.

Leino, P. I., Berg, M. A., \& Puska, P. (1994). Is back pain increasing? Results from national surveys in Finland during 1978/9-1992. Scandinavian Journal of Rheumatology, 23, 269276.

Lian, Y., Xiao, J., Liu, Y., Ning, L., Guan, S., Ge, H., \& Liu, J. (2015). Associations between insomnia, sleep duration and poor work ability. Journal of Psychosomatic Research, 78, $45-51$.

Lin, S., Wang, Z., \& Wang, M. (2006). Work ability of workers in western China: reference data. Occupational Medicine, 56, 89-93.

Lindegård, A., Larsman, P., Hadzibajramovic, E., \& Ahlborg, G. (2014). The influence of perceived stress and musculoskeletal pain on work performance and work ability in Swedish health care workers. International Archives of Occupational and Environmental Health, 87, 373-379.

Lindfors, P. M., Meretoja, O. A., Töyry, S. M., Luukkonen, R. A., Elovainio, M. J., \& Leino, T. J. (2007). Job satisfaction, work ability and life satisfaction among Finnish anaesthesiologists. Acta Anaesthesiologica Scandinavica, 51, 815-822.4

Mache, S., Danzer, G., Klapp, B. F., \& Groneberg, D. A. (2013). Surgeons’ work ability and performance in surgical care: relations between organisational predictors, work engagement and work ability. Langenbeck's Archives of Surgery, 398, 317-325.

Mache, S., Vitzthum, K., Klapp, B. F., \& Danzer, G. (2014). Surgeons' work engagement: Influencing factors and relations to job and life satisfaction. The Surgeon, 12, 181-190. 


\section{WORK ABILITY REVIEW}

Manchikanti, L., Singh, V., Datta, S., Cohen, S. P., \& Hirsch, J. A. (2008). Comprehensive review of epidemiology, scope, and impact of spinal pain. Pain Physician, 12, 35-70.

Martus, P., Jakob, O., Rose, U., Seibt, R., \& Freude, G. (2010). A comparative analysis of the Work Ability Index. Occupational Medicine, 60, 517-524.

Martinez, M. C., \& Latorre, M. D. R. D. D. (2006). Health and work ability among office workers. Revista de Saúde Pública, 40, 851-858.

Marqueze, E. C., Voltz, G. P., Borges, F. N., \& Moreno, C. R. (2008). A 2-year follow-up study of work ability among college educators. Applied Ergonomics, 39, 640-645.

Mazloumi, A., Rostamabadi, A., Saraji, G. N., \& Foroushani, A. R. (2012). Work ability index (WAI) and its association with psychosocial factors in one of the petrochemical industries in Iran. Journal of Occupational Health, 54, 112-118.

McDonald, R. B. (1988). The physiological aspects of aging. In H. Dennis (Ed.), Fourteen steps in managing an aging workforce (pp. 39-51). Lexington, MA: Lexington Books.

McGonagle, A.K., Barnes-Farrell, J.L., Di Milia, L., Fischer, F.M., Hobbs, B., Iskra-Golec, I., Kaliterna, L., \& Smith, L. (2014). Demands, resources, and work ability: A cross-national examination of health care workers. European Journal of Work and Organizational Psychology, 23, 830-846.

McGonagle, A.K., Fisher, G.G., Barnes-Farrell, J.L., and Grosch, J.W. (2015). Individual and work factors related to perceived work ability and labor force outcomes. Journal of Applied Psychology, 100, 376-398.

Meijman, T. F., \& Mulder, G. (1998). Psychological aspects of workload. In P.J.D. Drenth, H. Thierry, \& C.J. Wolff (Eds.), Handbook of Work and Organizational Psychology (pp.533). Hove, UK: Psychology Press. 


\section{WORK ABILITY REVIEW}

Milani, D., \& Monteiro, M. S. (2012). Musculoskeletal symptoms and work ability among agricultural machinery operators. Work, 41, 5721-5724.

Milosevic, M., Golubic, R., Knezevic, B., Golubic, K., Bubas, M., \& Mustajbegovic, J. (2011). Work ability as a major determinant of clinical nurses' quality of life. Journal of Clinical Nursing, 20, 2931-2938.

Monteiro, M. S., \& Alexandre, N. M. C. (2009). Work ability and low back pain among workers from a public health institution. Revista Gaúcha de Enfermagem, 30, 297-302.

Morschhäuser, M., \& Sochert, R. (2006). Healthy work in an ageing Europe. Federal Association of Company Health Insurance Funds, Essen, Germany, 1-76.

Müller, A., Heiden, B., Herbig, B., Poppe, F., \& Angerer, P. (2016). Improving well-being at work: A randomized controlled intervention based on selection, optimization, and compensation. Journal of Occupational Health Psychology, 21, 169-181.

Müller, A., \& Weigl, M. (2015). Selection, optimization, and compensation at work in relation to age. Encyclopedia of Geropsychology, 1-7.

Müller, A., Weigl, M., Heiden, B., Glaser, J., \& Angerer, P. (2012). Promoting work ability and well-being in hospital nursing: The interplay of age, job control, and successful ageing strategies. Work, 41, 5137-5144.

Müller, A., Weigl, M., Heiden, B., Herbig, B., Glaser, J., \& Angerer, P. (2013). Selection, optimization, and compensation in nursing: exploration of job-specific strategies, scale development, and age-specific associations to work ability. Journal of Advanced Nursing, 69, $1630-1642$. 


\section{WORK ABILITY REVIEW}

Neupane, S., Virtanen, P., Leino-Arjas, P., Miranda, H., Siukola, A., \& Nygård, C. H. (2013). Multi-site pain and working conditions as predictors of work ability in a 4-year follow-up among food industry employees. European Journal of Pain, 17, 444-451.

Ng, T.W.H, \& Feldman, D.C. (2015). The moderating effects of age in the relationships of job autonomy to work outcomes. Work, Aging, and Retirement, 1, 64-78.

Ng, T.W.H, \& Feldman, D.C. (2013). Employee age and health. Journal of Vocational Behavior, $83,336-345$.

Notenbomer, A., Groothoff, J. W., van Rhenen, W., \& Roelen, C. A. M. (2015). Associations of work ability with frequent and long-term sickness absence. Occupational Medicine, 65, 373-379.

Nübling, M., Hasselhorn, H. M., Seitsamo, J., \& Ilmarinen, J. (2004, October). Comparing the use of the short and the long disease list in the Work Ability Index Questionnaire. In Proceedings of the 2nd Symposium on Work Ability (p. 74). ICOH.

Nygård, C. H., Eskelinen, L., Suvanto, S., Tuomi, K., \& Ilmarinen, J. (1991). Associations between functional capacity and work ability among elderly municipal employees. Scandinavian Journal of Work, Environment \& Health, 17, 122-127.

Ohta, M., Eguchi, Y., Inoue, T., Honda, T., Morita, Y., Konno, Y., \& Kumashiro, M. (2015). Effects of bench step exercise intervention on work ability in terms of cardiovascular risk factors and oxidative stress: a randomized controlled study. International Journal of Occupational Safety and Ergonomics, 21, 141-149.

Padula, R. S., de Moraes, M. V., Chiavegato, L. D., \& Cabral, C. M. N. (2012). Gender and age do not influence the ability to work. Work, 41, 4330-4332. 


\section{WORK ABILITY REVIEW}

Palermo, J., Fuller-Tyszkiewicz, M., Walker, A., \& Appannah, A. (2013). Primary-and secondary-level organizational predictors of work ability. Journal of Occupational Health Psychology, 18, 220-229.

Perry, E. L., Dokko, G., \& Golom, F. (2012). The aging worker and person-environment fit. In J. W. Hedge \& W. C. Borman (Eds.), The Oxford Handbook of Work and Aging. Oxford, UK: Oxford University Press.

Peters, V., Houkes, I., de Rijk, A. E., Bohle, P. L., Engels, J. A., \& Nijhuis, F. J. (2016). Which resources moderate the effects of demanding work schedules on nurses working in residential elder care? A longitudinal study. International Journal of Nursing Studies, 58, $31-46$.

Pit, S. W., \& Hansen, V. (2014). Factors influencing early retirement intentions in Australian rural general practitioners. Occupational Medicine, 64, 297-304.

Phongamwong, C., \& Deema H. (2015). The impact of multi-site musculoskeletal pain on work ability among health care providers. Journal of Occupational Medicine and Toxicology, $1,1-10$.

Pohjonen, T. (2001). Perceived work ability of home care workers in relation to individual and work-related factors in different age groups. Occupational Medicine, 51, 209-217.

Pranjić, N., Maleš-Bilić, L., Beganlić, A., \& Mustajbegović, J. (2006). Mobbing, stress, and work ability index among physicians in Bosnia and Herzegovina: survey study. Croatian Medical Journal, 47, 750-758.

Prochnow, J. E., Tunmer, W. E., \& Chapman, J. W. (2013). A longitudinal investigation of the influence of literacy-related skills, reading self-perceptions, and inattentive behaviours on 


\section{WORK ABILITY REVIEW}

the development of literacy learning difficulties. International Journal of Disability, Development and Education, 60, 185-207.

Radkiewicz, P., Widerszal-Bazyl, M., \& NEXT-Study Group. (2005). Psychometric properties of Work Ability Index in the light of comparative survey study. International Congress Series, 1280, 304-309.

Reeuwijk, K. G., Robroek, S. J., Niessen, M. A., Kraaijenhagen, R. A., Vergouwe, Y., \& Burdorf, A. (2015). The prognostic value of the work ability index for sickness absence among office workers. PloS one, 10, e0126969. https://doi.org/10.1371/journal.pone.0126969

Riedel, N., Müller, A., \& Ebener, M. (2015). Applying strategies of selection, optimization, and compensation to maintain work ability—a psychosocial resource complementing the Job Demand-Control Model? Results from the representative lid: A cohort study on work, age, and health in Germany. Journal of Occupational and Environmental Medicine, 57, $552-561$.

Roelen, C. A., Heymans, M. W., Twisk, J. W., van der Klink, J. J., Groothoff, J. W., \& van Rhenen, W. (2014). Work Ability Index as tool to identify workers at risk of premature work exit. Journal of Occupational Rehabilitation, 24, 747-754.

Roelen, C. A., Van Rhenen, W., Groothoff, J. W., Van der Klink, J. J., Twisk, J. W., \& Heymans, M. W. (2014). Work ability as prognostic risk marker of disability pension: single-item work ability score versus multi-item work ability index. Scandinavian Journal of Work, Environment \& Health. 40, 428-431. 


\section{WORK ABILITY REVIEW}

Rongen, A., Robroek, S. J., Schaufeli, W., \& Burdorf, A. (2014). The contribution of work engagement to self-perceived health, work ability, and sickness absence beyond health behaviors and work-related factors

Rotenberg, L., Griep, R. H., Fischer, F. M., Fonseca, M. D. J. M., \& Landsbergis, P. (2009). Working at night and work ability among nursing personnel: when precarious employment makes the difference. International Archives of Occupational and Environmental Health, 82, 877-885.

Ruitenburg, M. M., Frings-Dresen, M. H., \& Sluiter, J. K. (2012). The prevalence of common mental disorders among hospital physicians and their association with self-reported work ability: a cross-sectional study. BMC Health Services Research, 12, 292-298.

Safari, S., Akbari, J., Kazemi, M., Mououdi, M. A., \& Mahaki, B. (2013). Personnel's health surveillance at work: effect of age, body mass index, and shift work on mental workload and work ability index. Journal of Environmental and Public Health, 2013. http://dx.doi.org/10.1155/2013/289498

Sahlin, E., Ahlborg, G., Matuszczyk, J. V., \& Grahn, P. (2014). Nature-based stress management course for individuals at risk of adverse health effects from work-related stress-effects on stress related symptoms, workability and sick leave. International Journal of Environmental Research and Public Health, 11, 6,586-6,611.

Salonen, P., Arola, H., Nygård, C. H., Huhtala, H., \& Koivisto, A. M. (2003). Factors associated with premature departure from working life among ageing food industry employees. Occupational Medicine, 53, 65-68. 


\section{WORK ABILITY REVIEW}

Schouten, L. S., Bültmann, U., Heymans, M. W., Joling, C. I., Twisk, J. W., \& Roelen, C. A. (2015). Shortened version of the work ability index to identify workers at risk of longterm sickness absence. The European Journal of Public Health, 26, 301-305.

Sell, L., Lund, H. L., Holtermann, A., \& Søgaard, K. (2014). The interactions between pain, pain-related fear of movement and productivity. Occupational Medicine, 64, 376-381.

Shiri, R., Kaila-Kangas, L., Ahola, K., Kivekäs, T., Viikari-Juntura, E., Heliövaara, M., \& LeinoArjas, P. (2013). The relation of co-occurring musculoskeletal pain and depressive symptoms with work ability. Journal of Occupational and Environmental Medicine, 55, $1,281-1,285$.

Shiri, R., Lallukka, T., Karppinen, J., \& Viikari-Juntura, E. (2014). Obesity as a risk factor for sciatica: a meta-analysis. American Journal of Epidemiology, 179, 929-937.

Siegrist, J. (1996). Adverse health effects of high-effort/low-reward conditions. Journal of Occupational Health Psychology, 1, 27-42.

Sjögren-Rönkä, T., Ojanen, M. T., Leskinen, E. K., Mustalampi, S. T., \& Mälkiä, E. A. (2002). Physical and psychosocial prerequisites of functioning in relation to work ability and general subjective well-being among office workers. Scandinavian Journal of Work, Environment \& Health, 28, 184-190.

Sorić, M., Golubić, R., Milošević, M., Juras, K., \& Mustajbegović, J. (2013). Shift work, quality of life and work ability among Croatian hospital nurses. Collegium Antropologicum, 37, $379-384$.

Sormunen, E., Remes, J., Hassi, J., Pienimaki, T., \& Rintamaki, H., (2009). Factors associated with self-estimated work ability and musculoskeletal symptoms among male and female workers in cooled food-processing facilities. Industrial Health, 47, 271-282. 


\section{WORK ABILITY REVIEW}

Sörensen, L. E., Pekkonen, M. M., Männikkö, K. H., Louhevaara, V. A., Smolander, J., \& Alén, M. J. (2008). Associations between work ability, health-related quality of life, physical activity and fitness among middle-aged men. Applied Ergonomics, 39, 786-791.

Stordeur, S., \& D'hoore, W. (2007). Organizational configuration of hospitals succeeding in attracting and retaining nurses. Journal of Advanced Nursing, 57, 45-58.

Sugimura, H., \& Thériault, G. (2010). Impact of supervisor support on work ability in an IT company. Occupational Medicine, 60, 451-457.

Truxillo, D. M., Cadiz, D. M., \& Hammer, L. B. (2015). Supporting the aging workforce: A review and recommendations for workplace intervention research. Annual Review of Organizational Psychology and Organizational Behavior, 2, 351-381.

Tuomi, K., Ilmarinen, J., Eskelinen, L., Järvinen, E., Toikkanen, J., \& Klockars, M. (1991). Prevalence and incidence rates of diseases and work ability in different work categories of municipal occupations. Scandinavian Journal of Work, Environment \& Health, 17, 6774.

Tuomi, K., Järvinen, E., Eskelinen, L., Ilmarinen, J., \& Klockars, M. (1991). Effect of retirement on health and work ability among municipal employees. Scandinavian Journal of Work, Environment \& Health, 17, 75-81.

Tuomi, K., Huuhtanen, P., Nykyri, E., \& Ilmarinen, J. (2001). Promotion of work ability, the quality of work and retirement. Occupational Medicine-Oxford, 51, 318-324.

Tuomi, K., Ilmarinen, J., Seitsamo, J., Huuhtanen, P., Martikainen, R., Nygard, C.H., \& Klockars, M. (1997). Summary of the Finnish research project (1981-1992) to promote the health and work ability of aging workers. Scandinavian Journal of Work, Environment and Health, 23, 66-71. 


\section{WORK ABILITY REVIEW}

Tuomi, K., Vanhala, S., Nykyri, E., \& Janhonen, M. (2004). Organizational practices, work demands and the well-being of employees: a follow-up study in the metal industry and retail trade. Occupational Medicine, 54, 115-121. Doi: 10.1093/occmed/kqh005

van den Berg, T. I., Alavinia, S. M., Bredt, F. J., Lindeboom, D., Elders, L. A., \& Burdorf, A. (2008). The influence of psychosocial factors at work and life style on health and work ability among professional workers. International Archives of Occupational and Environmental Health, 81, 1,029-1,036.

van den Berg, T. I., Robroek, S. J., Plat, J. F., Koopmanschap, M. A., \& Burdorf, A. (2011). The importance of job control for workers with decreased work ability to remain productive at work. International Archives of Occupational and Environmental Health, 84, 705-712.

van den Heuvel, S. G., \& van der Beek, A. J. (2014). The influence of chronic health problems on work ability and productivity at work: a longitudinal study among older employees. Scandinavian Journal of Work, Environment \& Health, 40, 473-487.

van Holland, B. J., Soer, R., de Boer, M. R., Reneman, M. F., \& Brouwer, S. (2015). Workers' health surveillance in the meat processing industry: work and health indicators associated with work ability. Journal of Occupational Rehabilitation, 25, 618-626.

Vasconcelos, S. P., Fischer, F. M., Reis, A. O. A., \& Moreno, C. R. D. C. (2011). Factors associated with work ability and perception of fatigue among nursing personnel from Amazonia. Revista Brasileira de Epidemiologia, 14, 688-697.

Vedovato, T. G., \& Monteiro, I. (2014). Health conditions and factors related to the work ability of teachers. Industrial Health, 52, 121-128.

Voltmer, J. B., \& Deller, J. (2018). Measuring Work Ability with Its Antecedents: Evaluation of the Work Ability Survey. Journal of Occupational Rehabilitation, 28, 307-321. 


\section{WORK ABILITY REVIEW}

von Bonsdorff, M. E., Huuhtanen, P., Tuomi, K., \& Seitsamo, J. (2009). Predictors of employees' early retirement intentions: an 11-year longitudinal study. Occupational Medicine, 60, 94-100.

von Bonsdorff, M. B., Seitsamo, J., Ilmarinen, J., von Bonsdorff, M. E., \& Taina, R. (2012). Work ability as a determinant of old age disability severity: Evidence from the 28-year Finnish Longitudinal Study on Municipal Employees. Aging Clinical and Experimental Research, 24, 354-360. Doi:10.1093/occmed/kqh005.

von Bonsdorff, M. E., von Bonsdorff, M. B., Zhou, Z. E., Kauppinen, M., Miettinen, M., Rantanen, T., \& Vanhala, S. (2014). Organizational justice, selection, optimization with compensation, and nurses' work ability. Journal of Occupational and Environmental Medicine, 56, 326-330.

von Bonsdorff, M. B., Seitsamo, J., Ilmarinen, J., Nygård, C. H., von Bonsdorff, M. E., \& Rantanen, T. (2011). Work ability in midlife as a predictor of mortality and disability in later life: a 28-year prospective follow-up study. Canadian Medical Association Journal, 183, E235-E242.

von Bonsdorff, M. E., Zhou, L., Wang, M., Vanhala, S., von Bonsdorff, M. B., \& Rantanen, T. (2016). Employee age and company performance: An integrated model of aging and human resource management practices. Journal of Management. Doi:

\section{$10.1177 / 0149206316662314$}

von Thiele Schwarz, U., Lindfors, P., \& Lundberg, U. (2008). Health-related effects of worksite interventions involving physical exercise and reduced workhours. Scandinavian Journal of Work, Environment \& Health, 34, 179-188. 


\section{WORK ABILITY REVIEW}

Vuori, J., Toppinen-Tanner, S., \& Mutanen, P. (2012). Effects of resource-building group intervention on career management and mental health in work organizations: randomized controlled field trial. Journal of Applied Psychology, 97, 273-286.

Walker, E. J., Jackson, C. A., Egan, H. H., \& Tonkin, M. (2015). Workability and mental wellbeing among therapeutic prison officers. Occupational Medicine, 65, 549-551.

Weigl, M., Müller, A., Hornung, S., Zacher, H., \& Angerer, P. (2013). The moderating effects of job control and selection, optimization, and compensation strategies on the age-work ability relationship. Journal of Organizational Behavior, 34, 607-628.

Wu, S., Li, J., Wang, M., Wang, Z., \& Li, H. (2006). Intervention on occupational stress among teachers in the middle schools in China. Stress and Health, 22, 329-336.

Yong, M., Nasterlack, M., Pluto, R. P., Elmerich, K., Karl, D., \& Knauth, P. (2010). Is health, measured by work ability index, affected by 12-hour rotating shift schedules? Chronobiology International, 27, 1,135-1,148. 


\section{WORK ABILITY REVIEW}

Table 1.

Overview of Extant Work Ability Measures

\begin{tabular}{|c|c|c|c|c|}
\hline Measure & $\begin{array}{c}\text { Number of } \\
\text { Questions }\end{array}$ & $\begin{array}{l}\text { Measure Content and } \\
\text { Dimension Scores }\end{array}$ & Scoring & Comments \\
\hline \multicolumn{5}{|c|}{ Combined Objective and Perceived Measures } \\
\hline $\begin{array}{l}\text { Work Ability Index } \\
\text { (WAI) } \\
\text { (Tuomi, Ilmarinen, } \\
\text { Jahkola, Katajarinne, \& } \\
\text { Tulkki, 1998) }\end{array}$ & $\begin{array}{l}9 \text { single response } \\
\text { questions plus a } \\
\text { checklist of } 51 \\
\text { possible diseases, } \\
\text { injuries, and } \\
\text { illnesses ( } 60 \text { total } \\
\text { questions) }\end{array}$ & $\begin{array}{l}\text {-Current work ability compared with } \\
\text { lifetime best (range: } 0-10 \text { ) } \\
\text {-Work ability in relation to a) mental } \\
\text { and b) physical job demands (2-10) } \\
\text {-Number of physician-diagnosed } 51 \\
\text { listed diseases, injuries, and illnesses } \\
\text { current diseases (1-7 based on the } \\
\text { checklist responses) } \\
\text {-Estimated work impairment due to } \\
\text { diseases (1-6) } \\
\text {-Sickness leave during last } 12 \\
\text { months (1-5) } \\
\text {-Own prognosis of work ability } 2 \\
\text { years from now (1-7) } \\
\text {-Mental resources (1-4) }\end{array}$ & $\begin{array}{l}\text {-Scores are summed. } \\
\text {-Scores range from 7-49, } \\
\text { categorized as: } \\
\text { Poor }=7-27 \\
\text { Moderate }=28-36 \\
\text { Good }=37-43 \\
\text { Excellent }=44-49\end{array}$ & $\begin{array}{l}\text {-Uses and combines multiple } \\
\text { response formats and different } \\
\text { weightings. } \\
\text {-Combines objective and perceived } \\
\text { measures of WA. } \\
\text {-Relatively arbitrary categorization of } \\
\text { respondents WA categories. } \\
\text {-Lengthy and requires disclosure of } \\
\text { personal health information, affecting } \\
\text { practicality. } \\
\text {-Satisfactory test-retest reliability. }\end{array}$ \\
\hline $\begin{array}{l}\text { Work Ability Index } \\
\text { Short Form (Nübling, } \\
\text { Hasselhorn, Seitsamo, } \\
\text { \& Ilmarinen, 2004). }\end{array}$ & $\begin{array}{l}9 \text { single response } \\
\text { questions plus a } \\
\text { checklist of } 13 \\
\text { possible diseases, } \\
\text { injuries, and } \\
\text { illnesses ( } 22 \text { total } \\
\text { questions) }\end{array}$ & $\begin{array}{l}\text {-Current work ability compared with } \\
\text { lifetime best (range: } 0 \text {-10) } \\
\text {-Work ability in relation to a) mental } \\
\text { and b) physical job demands (2-10) } \\
\text { - Number of physician-diagnosed } 13 \\
\text { categories of diseases, injuries, and } \\
\text { illnesses current diseases (1-7 based } \\
\text { on the checklist responses) } \\
\text {-Estimated work impairment due to } \\
\text { diseases (1-6) } \\
\text {-Sickness leave during last } 12 \\
\text { months (1-5) } \\
\text {-Own prognosis of work ability } 2 \\
\text { years from now (1-7) }\end{array}$ & $\begin{array}{l}\text {-Scores are summed. } \\
\text {-Scores range from 7-49, } \\
\text { categorized as: } \\
\text { Poor }=7-27 \\
\text { Moderate }=28-36 \\
\text { Good }=37-43 \\
\text { Excellent }=44-49\end{array}$ & $\begin{array}{l}\text {-Similar to the WAI, uses different } \\
\text { response scales and weightings, } \\
\text { combines objective and perceived } \\
\text { measures, includes personal health } \\
\text { information, and categorizes } \\
\text { respondents into relatively arbitrary } \\
\text { WA categories. } \\
\text {-Number of items is reduced. } \\
\text {-Satisfactory test-retest reliability. }\end{array}$ \\
\hline
\end{tabular}




\section{WORK ABILITY REVIEW}

\begin{tabular}{|c|c|c|c|c|}
\hline & & -Mental resources (1-4) & & \\
\hline \multicolumn{5}{|c|}{ Perceived Measures } \\
\hline $\begin{array}{l}\text { Work Ability Score } \\
\text { (Tuomi, Ilmarinen, } \\
\text { Jahkola, Katajarinne, \& } \\
\text { Tulkki, 1998; Ahlstrom, } \\
\text { Grimby-Ekman, } \\
\text { Hagberg, \& Delve, } \\
\text { 2010; El Fassi et al., } \\
\text { 2013) }\end{array}$ & 1 & $\begin{array}{l}\text {-One's perceived present work } \\
\text { ability compared to lifetime best } \\
(0-10)\end{array}$ & $\begin{array}{l}\text {-Higher score indicates higher } \\
\text { work ability }\end{array}$ & $\begin{array}{l}\text {-Only } 1 \text { item which may not fully } \\
\text { capture the WA concept. } \\
\text {-Psychometrically limited as it is only } \\
1 \text { item. } \\
\text { - Predictive utility versus other } \\
\text { measures of WA and nomological } \\
\text { network has not been fully explored. - } \\
\text { Treats WA as a continuous variable. }\end{array}$ \\
\hline $\begin{array}{l}\text { Work Ability Estimate } \\
\text { (Ilmarinen, Gould, } \\
\text { Jarvikoski, \& Jarvisalo, } \\
\text { 2008) }\end{array}$ & 1 & $\begin{array}{l}\text {-The extent to which one perceives } \\
\text { oneself as generally fit to work } \\
\text { versus disabled } \\
\text {-this one-item measure has three } \\
\text { possible response options: 1) } \\
\text { completely fit for work, 2) partially } \\
\text { disabled for work, and 3) completely } \\
\text { disabled for work }\end{array}$ & $\begin{array}{l}\text {-Treated as a categorical } \\
\text { variable; an individual is simply } \\
\text { categorized as "completely fit } \\
\text { for work", "partially disabled } \\
\text { for work", or "completely } \\
\text { disabled for work" depending } \\
\text { on their response }\end{array}$ & $\begin{array}{l}\text {-Only } 1 \text { item which may not fully } \\
\text { capture the WA concept and the } \\
\text { predictive utility versus other } \\
\text { measures of WA and nomological } \\
\text { network has not been fully explored. - } \\
\text { Three categories of WA. } \\
\text {-Single-item indicator so it is } \\
\text { psychometrically limited. }\end{array}$ \\
\hline $\begin{array}{l}\text { Two-Item Work Ability } \\
\text { Scale (Weigl, Muller, } \\
\text { Hornung, Zacher, \& } \\
\text { Angerer, 2013) }\end{array}$ & 2 & $\begin{array}{l}\text {-Work ability in relation to a) mental } \\
\text { and b) physical job demands of the } \\
\text { job (range }=1 \text { [very poor] to } 5 \text { [very } \\
\text { good]) }\end{array}$ & $\begin{array}{l}\text {-Scale score is the mean of the } \\
\text { two items, with higher scores } \\
\text { signifying higher levels of work } \\
\text { ability }\end{array}$ & $\begin{array}{l}\text {-As opposed to the original } \\
\text { conceptualizations of WA, captures } \\
\text { only mental and physical job demands } \\
\text { and does not consider personal and } \\
\text { organizational factors. -The } \\
\text { predictive utility versus other } \\
\text { measures of WA and nomological } \\
\text { network has not been fully explored, } \\
\text { but did show expected relationships } \\
\text { with psychological variables and } \\
\text { acceptable reliability. }\end{array}$ \\
\hline
\end{tabular}


WORK ABILITY REVIEW

\begin{tabular}{|c|c|c|c|c|}
\hline $\begin{array}{l}\text { Perceived Work Ability } \\
\text { (PWA) } \\
\text { (McGonagle, Fisher, } \\
\text { Barnes-Farrell, \& } \\
\text { Grosch, 2015) }\end{array}$ & 4 & $\begin{array}{l}\text {-Current work ability compared to } \\
\text { lifetime best } \\
\text {-Work ability in relation to physical } \\
\text { demands } \\
\text {-Work ability in relation to mental } \\
\text { demands } \\
\text {-Work ability in relation to } \\
\text { interpersonal demands } \\
\text {-Response scale ranges from } 0 \\
\text { (cannot perform current work at all) } \\
\text { to } 10 \text { (work ability at its lifetime } \\
\text { best) }\end{array}$ & $\begin{array}{l}\text {-Scale score is the mean of the } \\
\text { four items with higher score } \\
\text { indicating higher levels of work } \\
\text { ability }\end{array}$ & $\begin{array}{l}\text {-Utilizes the JD-R framework as a } \\
\text { theoretical foundation. } \\
\text {-Strictly focuses on perceived WA } \\
\text { including current WA as well as } \\
\text { physical, mental, and interpersonal } \\
\text { demands relative to WA. } \\
\text {-Construct validation evidence } \\
\text { regarding factor structure, convergent } \\
\text { and discriminant validity, and } \\
\text { reliability. } \\
\text {-Additional nomological network } \\
\text { research is needed. }\end{array}$ \\
\hline
\end{tabular}




\section{WORK ABILITY REVIEW}

Table 2.

Overview of WA Workplace Interventions

\begin{tabular}{|c|c|c|c|}
\hline Category & Intervention & Research Examples & Relevant Related Research/Theory \\
\hline \multirow[t]{2}{*}{ Individual } & $\begin{array}{l}\text { Increase physical } \\
\text { activity inside or } \\
\text { outside of work } \\
\text { hours }\end{array}$ & $\begin{array}{l}\text { Positive relationship observed } \\
\text { between physical activity and WA } \\
\text { (Flannery, Resnick, \& McMullen, } \\
\text { 2012; Leino et al., 1994; Ohta et al., } \\
\text { 2015; Pohjonen \& Ranta, 2001) }\end{array}$ & $\begin{array}{l}\text { Physical activity enables individuals to gain more } \\
\text { physical resources such as increased energy and } \\
\text { physical capacity which directly targets an } \\
\text { individual's WA. }\end{array}$ \\
\hline & Stress management & $\begin{array}{l}\text { Positive relationship observed } \\
\text { between stress management and } \\
\text { WA (McGonagle et al., 2014a; } \\
\text { Sahlin et al., 2014; Wu et al., 2006) }\end{array}$ & $\begin{array}{l}\text { Reduction of mental drains allows for increased } \\
\text { mental resources to allocate to adaptive behaviors } \\
\text { like selection, optimization, and compensation. }\end{array}$ \\
\hline \multirow{3}{*}{$\begin{array}{l}\text { Group \& } \\
\text { Organization } \\
\text { Level }\end{array}$} & $\begin{array}{l}\text { Employee } \\
\text { preparedness for } \\
\text { career management }\end{array}$ & $\begin{array}{l}\text { Positive relationship between } \\
\text { training for career preparedness and } \\
\text { WA (Vouri et al., 2012). }\end{array}$ & $\begin{array}{l}\text { Increased preparedness allows for selection and } \\
\text { compensation behaviors to be planned for and } \\
\text { implemented. }\end{array}$ \\
\hline & $\begin{array}{l}\text { Reducing work } \\
\text { hours for full time } \\
\text { employees }\end{array}$ & $\begin{array}{l}\text { Reduced hours resulted in increased } \\
\text { WA (Von Thiele Schwarz et al., } \\
\text { 2008) }\end{array}$ & $\begin{array}{l}\text { Reduction of work hours allows for longer physical } \\
\text { and mental recovery time resulting in greater levels } \\
\text { of personal resources available to allocate toward } \\
\text { adaptive behaviors that increase the ability to meet } \\
\text { work demands. }\end{array}$ \\
\hline & $\begin{array}{l}\text { Creating supportive } \\
\text { work conditions }\end{array}$ & $\begin{array}{l}\text { Increased supportive work } \\
\text { environment increased WA } \\
\text { (Ahlstrom et al., 2013) }\end{array}$ & $\begin{array}{l}\text { Increased job resources allows for the individual to } \\
\text { appropriately apply selection, optimization, and } \\
\text { compensation behaviors to allocate toward better } \\
\text { meeting job demands. }\end{array}$ \\
\hline
\end{tabular}




\section{WORK ABILITY REVIEW}

Table 3.

Overview of Future Directions of Work Ability

\begin{tabular}{|c|c|c|c|}
\hline Category & Sub-category & Examples & Relevant Related Research \\
\hline \multirow{5}{*}{ WA Concept Clarification } & $\begin{array}{l}\text { Nomological network } \\
\text { exploration for WA }\end{array}$ & $\begin{array}{l}\text { Examining incremental validity and } \\
\text { relative importance analysis against } \\
\text { variables like fit and self-efficacy }\end{array}$ & McGonagle et al (2015) \\
\hline & $\begin{array}{l}\text { Consistent measurement } \\
\text { of WA }\end{array}$ & $\begin{array}{l}\text { Development of valid and } \\
\text { theoretically rooted measures of } \\
\text { WA }\end{array}$ & $\begin{array}{l}\text { McGonagle et al (2015), } \\
\text { Imarinen et al (2015), Voltmer } \\
\text { and Deller (2017) }\end{array}$ \\
\hline & $\begin{array}{l}\text { Qualitative analysis of } \\
\text { work ability }\end{array}$ & $\begin{array}{l}\text { Conducting think aloud analysis of } \\
\text { those answering questions about } \\
\text { work ability }\end{array}$ & $\begin{array}{l}\text { Fonteyn, Kuipers, \& Grobe, } \\
1993\end{array}$ \\
\hline & Curvilinear relationships & $\begin{array}{l}\text { Examining how there could } \\
\text { potentially be the perfect level of } \\
\text { physical activity in a job to maintain } \\
\text { and promote work ability }\end{array}$ & Not to our knowledge \\
\hline & $\begin{array}{l}\text { Dynamic and reciprocal } \\
\text { influences of WA }\end{array}$ & $\begin{array}{l}\text { Examining how job attitudes and } \\
\text { well-being can be influenced as well } \\
\text { as influence WA over time }\end{array}$ & Not to our knowledge \\
\hline $\begin{array}{c}\text { Lifespan Development and } \\
\text { Theoretical Integration }\end{array}$ & $\begin{array}{l}\text { Selective optimization and } \\
\text { compensation theory }\end{array}$ & $\begin{array}{l}\text { Examining the different processes } \\
\text { that people enact to improve or } \\
\text { maintain their work ability }\end{array}$ & $\begin{array}{l}\text { Muller et al., 2012a; Muller et } \\
\text { al., 2012b; Muller et al., 2013; } \\
\text { Muller et al., 2015; Riedel et } \\
\text { al., 2015; von Bonsdorf et al., } \\
2014\end{array}$ \\
\hline
\end{tabular}


WORK ABILITY REVIEW

\begin{tabular}{|l|l|l|l|}
\hline & $\begin{array}{l}\text { Socioemotional selectivity } \\
\text { theory }\end{array}$ & $\begin{array}{l}\text { Examining changes in our social } \\
\text { motivations over time and how this } \\
\text { could influence work ability }\end{array}$ & Not to our knowledge \\
\hline \multirow{4}{*}{ Multi-level Approach to WA } & Organizational culture & $\begin{array}{l}\text { Investigating the influences of } \\
\text { organizational culture and climate } \\
\text { on WA }\end{array}$ & $\begin{array}{l}\text { Feldt et al., 2009; Larsson et } \\
\text { al., 2012; Palermo et al., 2013; } \\
\text { Tuomi et al., 2004 }\end{array}$ \\
\cline { 2 - 4 } & $\begin{array}{l}\text { Societal influences on } \\
\text { WA }\end{array}$ & $\begin{array}{l}\text { Studying the extent to which } \\
\text { societal norms and expectations } \\
\text { influence WA }\end{array}$ & Not to our knowledge \\
\cline { 2 - 5 } & Shared perceptions of WA & $\begin{array}{l}\text { Examining the extent to which } \\
\text { perceptions of WA can be } \\
\text { aggregated at different levels of } \\
\text { analysis }\end{array}$ & $\begin{array}{l}\text { Boehm et al., 2014; Kunze et } \\
\text { al., 2011 }\end{array}$ \\
\hline
\end{tabular}




\section{WORK ABILITY REVIEW}

Figure 1. Conceptual Integration of Objective and Perceived Work Ability with JD-R (Bakker \& Demerouti, 2007; McGonagle et al., 2015), SOC (Baltes \& Baltes, 1990), and SST (Carstensen et al., 1999)

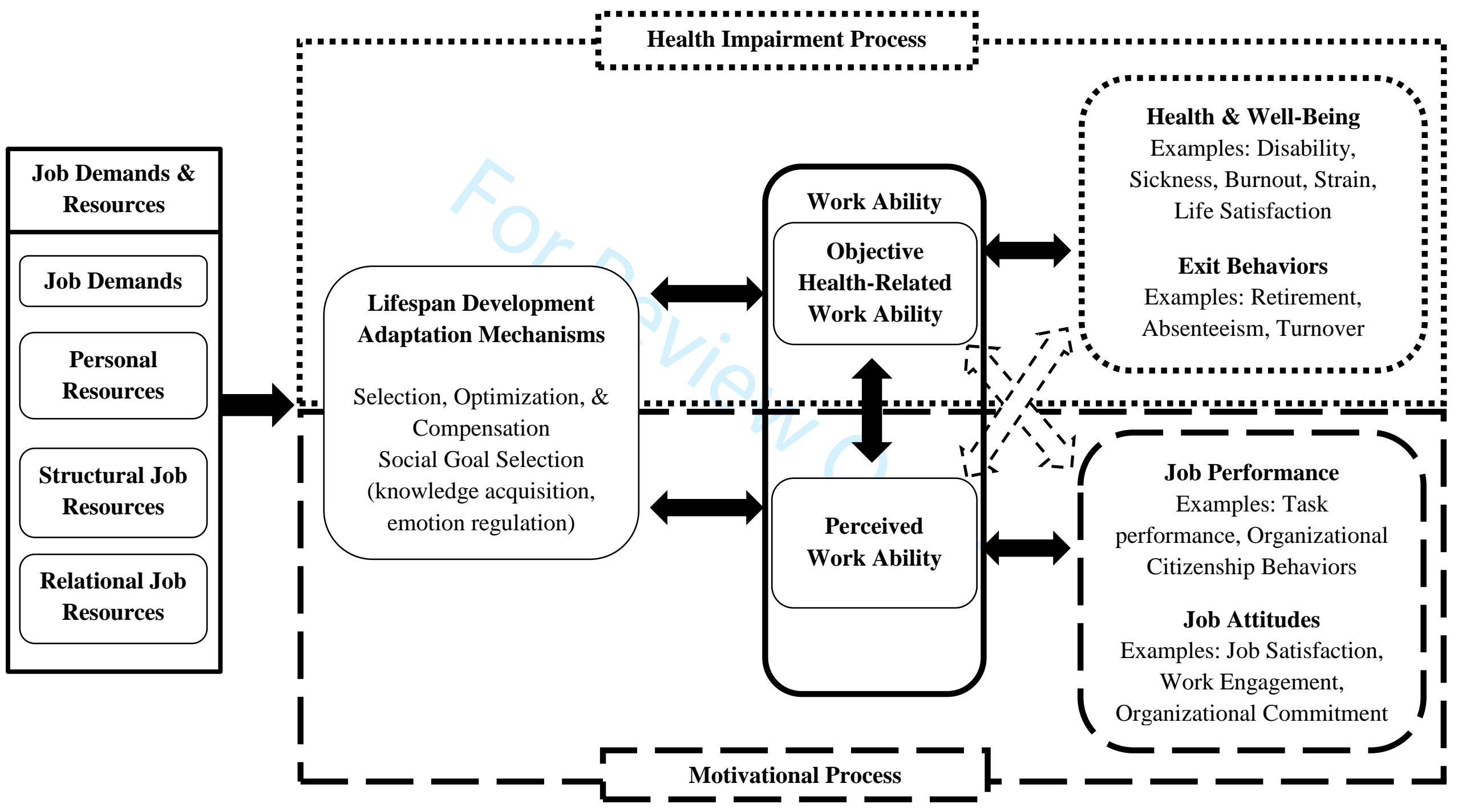

Notes. Black solid arrows from objective and perceived work ability to the outcomes indicate an expected stronger relationship. The box around the two components/facets of WA indicate that they are related to a single construct, but are distinct dimensions of WA. The dotted arrows from objective and perceived work ability indicate a weaker anticipated relationship. The dotted rectangle is aligned with the health impairment process in the JD-R model and the dashed rectangle

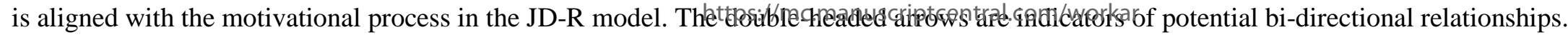

